\title{
Imiglucerase in the treatment of Gaucher disease: a history and perspective
}

\author{
This article was published in the following Dove Press journal: \\ Drug Design, Development and Therapy \\ 17 April 2012 \\ Number of times this article has been viewed
}

\section{Patrick B Deegan \\ Timothy M Cox}

Department of Medicine, University of Cambridge, Lysosomal Disorders Unit, Addenbrooke's NHS Foundation Hospitals Trust, Cambridge, UK
Correspondence: Timothy M Cox; Patrick B Deegan Department of Medicine, University of Cambridge, Lysosomal Disorders Unit, Addenbrooke's Hospital, Hills Road, Cambridge CB2 0QQ, UK Email tmc12@medschl.cam.ac.uk; patrick.deegan@addenbrookes.nhs.uk
Abstract: The scientific and therapeutic development of imiglucerase $\left(\right.$ Cerezyme $^{\circledR}$ ) by the Genzyme Corporation is a paradigm case for a critical examination of current trends in biotechnology. In this article the authors argue that contemporary interest in treatments for rare diseases by major pharmaceutical companies stems in large part from an exception among rarities: the astonishing commercial success of Cerezyme. The fortunes of the Genzyme Corporation, latterly acquired by global giant Sanofi SA, were founded on the evolution of a blockbuster therapy for a single but, as it turns out, propitious ultra-orphan disorder: Gaucher disease.

Keywords: enzyme therapy, ultra-orphan, macrophage targeting, lysosomal disease, mannose lectin, biopharmaceutical

\section{Introduction}

It is a long-established tradition in medicine to "treasure your exceptions": the study of rare forms of disease is not only informative but also almost invariably instructive. Although Gaucher disease was until quite recently an arcane specialism within disparate clinical fields including hematology, gastroenterology, pediatrics, and neurology, the efficacy of imiglucerase as an augmenting therapy for the hematological and visceral aspects of this disease has been transforming. Indeed, when the therapeutic benefits of imiglucerase as a vanguard orphan agent were noted by Gaucher patients and their physicians worldwide, the commercial treasure in Genzyme's exceptions rapidly lifted the corporation to iconic biotechnological status. As an ultra-orphan biologic, imiglucerase and its nonengineered predecessor, alglucerase, are exceptionally costly: at their height in 2009, annual revenues for imiglucerase approached $\$ 1,800,000,000$ (all figures given in US dollars), but despite a high profit margin, this income was obtained from the provision for fewer than 6000 patients worldwide.

While such success speaks for itself, it is salutary to explore the causal and historical factors that contribute to victory. The authors contend that had any lysosomal disease other than Gaucher disease been the principal object of Roscoe Brady and his colleagues' therapeutic interest, then no treatment for this class of disorders would have survived the vicissitudes of development and licensing. As a consequence of choices made many decades ago, seven enzyme treatments for lysosomal diseases have received marketing approval, and more are in late-stage clinical development. Introduction of enzyme therapy for lysosomal diseases internationally has greatly expanded the manufacturing expertise in biologics; now a multibillion-dollar industry, this ultra-orphan field has captured the interest of several large global corporations. 
Gaucher disease has unique features, which render it an ideal target for protein-based therapy, but the scientific odyssey that eventually led to effective treatment was circuitous and much prolonged. After Brady and collaborators ${ }^{1-3}$ at the National Institutes of Health (NIH) made the scientific "proof-of-principle" case with glucocerebrosidase extracted from human placentae, modifying the enzyme for in vivo targeting, the emerging Genzyme company industrialized the manufacture of the enzyme and successfully exploited the orphan drug legislation first to develop alglucerase (Ceredase $^{\circledR}$; Genzyme Corporation, Cambridge, MA). It was readily shown that macrophage-targeted enzyme therapy is strikingly effective in Gaucher disease: thus, a recombinant product, imiglucerase (Cerezyme ${ }^{\circledR}$; Genzyme), obtained from genetically engineered eukaryotic cells and similarly modified after purification, was soon introduced. With this development came a breathtaking economy of scale and high revenues from international sales that remain unprecedented in the field of orphan diseases. Not only did Genzyme make rapid progress with high-level reimbursement for an extremely costly treatment for individuals with an ultrarare disease but also it built on its commercial achievement after market authorization by continuing contributions to clinical practice and scientific research. The emblematic product, imiglucerase, has been joined in the marketplace by biosimilar glycoproteins obtained by application of novel genetic engineering techniques; moreover, innovative medicinal chemistry has brought orally active molecules with alternative therapeutic actions in Gaucher disease credibly within the clinical realm.

The enchanting story of enzyme therapy for Gaucher disease has taken several unanticipated turns. In June 2009, after 2 decades of growth and diversification of its commercial base, Genzyme lost the capacity to manufacture its core product. A catastrophic series of errors affecting the production facility for imiglucerase and other enzymes caused the loss of more than a third of the company's revenue. The reputation of the Genzyme Corporation, the world's third-largest biotechnology company was in jeopardy, and an unprecedented opportunity arose for market takeover of imiglucerase by biosimilar agents. One of these (velaglucerase alfa $\left[V^{2} I_{V}{ }^{\circledR}\right]$; Shire Human Genetic Therapies, St Helier, Jersey) has received international marketing authorization, and another (taliglucerase alfa; Pfizer Inc, New York, NY, and Protalix BioTherepeutics, Carmiel, Israel) is in latestage development. Nonetheless, with the partial recovery of Genzyme's facility and the recent acquisition of the corporation by Sanofi SA, the extent to which these new products can develop or maintain their position within the competitive microcosm is unresolved. This article reviews the developmental history of enzyme therapy for Gaucher disease and discloses the authors' perceptions of the principles most likely to sustain pharmaceutical success in the ultra-orphan arena.

\section{Gaucher disease pathogenesis: basis for therapeutic effect}

Gaucher disease is an inborn error of metabolism that results from deficiency of $\beta$-glucocerebrosidase (D-glucosyl- $N$ acylsphingosine glucohydrolase, EC 3.2.1.45), encoded by the human GBA1 gene. The enzyme, a lysosomal glycoprotein, is an acid $\beta$-glucosidase. The range of natural substrates of $\beta$-glucocerebrosidase are mixtures of $N$-acyl-sphingosyl-1-O- $\beta$-D glucosides with varying acyl (fatty acid) and sphingosine moieties, including those like glucosylsphingosine that are devoid of fatty acids; the enzyme cleaves glucosylceramide (also called glucocerebroside) into glucose and ceramide. Glucosylceramide accumulates within the lysosomes of cells, particularly macrophages and related cells. ${ }^{4,5}$ Gaucher disease is usually regarded as the most common lysosomal storage disease, occurring in approximately one in every 75,000 births worldwide. ${ }^{6,7}$ Inherited as an autosomal recessive disorder, the condition is more prevalent in populations of Ashkenazi Jewish descent: according to studies of gene frequency, there are estimated to be approximately 20,000 individuals carrying two diseaserelated mutations (in trans) in the United States alone; twothirds of these are of Ashkenazi origin. ${ }^{8}$ Not all of these individuals will develop symptomatic disease.

For operational purposes in clinical practice, Gaucher disease has conventionally been categorized into three clinical types. In all affected patients, the disease involves the visceral organs, bone marrow, and bone. Type 1 (Online Mendelian Inheritance in Man [OMIM] \#230800), the so-called non-neuronopathic disease, is the most prevalent. It is distinguished from types 2 (OMIM \#230900) and 3 (OMIM \#231000) - the acute neuronopathic and subacute neuropathic variants, respectively - by the lack of characteristic involvement of the brain. However, intermediate phenotypes occur, particularly between types 2 and $3 .{ }^{9}$ In addition, there are reports of several neurological manifestations in type 1 patients that are distinct from the specific features that define types 2 and $3 .^{10,11}$

The $7.6 \mathrm{~kb}$ GBAl gene is located on chromosome 1q2 and comprises eleven exons. A $5 \mathrm{~kb}$ unprocessed pseudogene is located $16 \mathrm{~kb}$ downstream. More than 200 distinct $G B A$ gene mutations are listed in the Human Gene 
Mutation Database (http://www.hgmd.cf.ac.uk/ac/all.php). Of these, more than $80 \%$ are single nucleotide substitutions. Complex alleles account for approximately $20 \%$ of mutations. ${ }^{12,13}$ Three mutant alleles, N370S (c.1226 A > G), L444P (c.1448T > C), and 84GG (c.84dupG), are the most prevalent. ${ }^{8}$ On account of its diverse phenotypic variability, prediction of disease severity based on genotype is only approximate. ${ }^{4,8}$ Individuals with one N370S allele are protected against neuronopathic disease, while homozygotes for L444P are likely to have neuronopathic features. Rare pathological features may accompany other mutations, such as the cardiovascular variant, which occurs in patients homozygous for the mutant human D409H allele. ${ }^{14,15}$

Acid glucocebrosidase activity localizes to the luminal side of the lysosomal membrane and shares properties with integral membrane proteins. The substrate, $\beta$-D-glucosylceramide (glucocerebroside), is a component of cell membranes and is widely abundant in circulating blood cells. The small sphingolipid activator protein, saposin $\mathrm{C}$, which is critical for activity of glucocerebrosidase in vivo, may present glucocerebroside to the enzyme, as reviewed by Locatelli Hoops et al. ${ }^{16}$ Deficiency of saposin C, which occurs only rarely, results in a severe but distinct form of Gaucher disease. ${ }^{4,16}$

In patients affected by Gaucher disease, the deficiency of glucosylceramidase leads to accumulation of glucocerebroside and other glycolipids within the lysosomes of macrophages and other phagocytic cells of the monocyte-macrophage lineage. The tissue concentration of these compounds may be increased 20-100 times. ${ }^{17}$ The unacylated congener of glucosylceramide, glucosylsphingosine, is particularly elevated in patients with neuronopathic Gaucher disease, and it may have a role in the pathogenesis of Gaucher disease as well as in neurodegeneration. ${ }^{18,19}$

Macrophages, pathologically engorged with glycolipid material, are known as Gaucher cells and are a cardinal feature of the disease..$^{20,21}$ In histological preparations stained by the Leishman method, Gaucher cells have a characteristic histological appearance of wrinkled tissue paper or crumpled silk. Membrane-bound inclusions filled with glucocerebroside are seen with electron microscopy. Gaucher cells have the protein expression profile of the so-called alternatively activated macrophage, a phenotype associated with chronic inflammation and fibrosis. ${ }^{22}$

As demonstrated by the effects of hematopoietic stem cell (bone marrow) transplantation, the clinical manifestations of Gaucher disease, with massive visceromegaly, are principally an indirect consequence of the accumulation of the pathological macrophages in the spleen, liver, and bone marrow. However, pathological lipid accumulation in macrophages accounts for less than $2 \%$ of the additional tissue mass in the liver and spleen; the additional increase is attributed to an inflammatory and infiltrative cellular response. ${ }^{23}$ Thrombocytopenia and anemia result from splenic sequestration, with a contribution from marrow failure, as shown by the long-term evolution of the disease after splenectomy. Growth failure, muscle wasting, and pubertal delay are features of the more general metabolic effects of the complex inflammatory response. ${ }^{24}$

Several pathological processes occur within bone: decreased mineral density, marrow infiltration, and infarction of bone. ${ }^{25}$ The mechanisms leading to decreased bone mineral density are uncertain, but they may involve failure to achieve peak bone mass, ${ }^{26}$ abnormal osteoclast regulation, or overproduction of cytokines/chemokines ${ }^{27}$ and proteases ${ }^{28}$ by activated macrophages.

In neuronopathic variants of Gaucher disease, profound failure of lysosomal sphingolipid breakdown leads to the accumulation of toxic macromolecules that originate from the rapid turnover of membrane gangliosides in neural cells. Occasional Gaucher cells are found in the Virchow-Robin spaces and sporadically within deep layers of the cerebral cortex and cerebellum. Neuronal death and neuronophagia by activated microglia occur in selected midbrain, brainstem, and cerebellar nuclei - changes that are accompanied by reactive astrogliosis. ${ }^{29,30}$

Delivery of many soluble lysosomal proteins to the lysosome is mediated by mannose 6-phosphate receptors and depends on the trafficking of the receptor to early endosomes in a manner requiring the interaction of its cytosolic domain with the GGAs (Golgi-localized gamma-ear containing, ADP-ribosylation factor binding family of multidomain coat proteins). These are highly conserved monomeric clathrin adaptor proteins that orchestrate the trafficking of the mannose 6-phosphate receptors and other cargo molecules from the trans-Golgi network to the endosome-lysosome system. When the mannose 6-phosphate pathway is defective, as in inclusion-cell (I-cell) disease, some soluble lysosomal proteins continue to traffic to the lysosomes: a protein, sortilin, is responsible for the independent targeting and has numerous cytosolic binding partners, including GGAs; the cytosolic domains of sortilin and mannose 6-phosphate receptors are functionally homologous and they share a common trafficking mechanism.

Sortilin mediates the trafficking of sphingolipid activator proteins, cathepsins $\mathrm{D}$ and $\mathrm{H}$, and acid sphingomyelinase. 
Renal podocyte uptake of the therapeutic enzyme preparations for Fabry disease is also partly mediated by sortilin. ${ }^{31}$ However, $\beta$-glucocerebrosidase and cathepsins $\mathrm{K}$ and $\mathrm{L}$ reach the lysosomes by a sortilin-independent process.

Once taken up by macrophages, the route of exogenous mannose-terminated acid $\beta$-glucocerebrosidase to the lysosome and related compartments is distinct from other lysosomal enzymes and shows marked cell/tissue selectivity. ${ }^{32}$ In humans it appears to be used principally in the brain and kidney as well as in fibroblasts; it is less active in peripheral leukocytes. Nascent $\beta$-glucocerebrosidase binds via specific residues to a chaperone molecule on the lysosomal membrane, LIMP-2 - a mannose-6-phosphate-independent trafficking receptor for $\beta$-glucocerebrosidase. Patients with mutations in LIMP-2 develop the action myoclonus-renal failure syndrome and there appears to be no involvement of the macrophage system; their fibroblasts are deficient in acid $\beta$-glucosidase activity but the deficient trafficking is not apparent in enzymatic assays using preparations of peripheral white blood cells. Other mannose-6-phosphateindependent trafficking receptors for $\beta$-glucocerebrosidase may be active in human tissues, especially hematopoietic tissues.

Notwithstanding, the pathway for delivery of $\beta$-glucocerebrosidase clearly differs from that utilized by many other lysosomal proteins, in which the insulin-like growth factor 2/cation-independent mannose 6-phosphate receptor or sortilin pathway participates. Therapeutic delivery of exogenous mannose-terminated $\beta$-glucocerebrosidase appears to follow a unique, high-capacity pathway with specificity for macrophages, which are an important pathological focus in Gaucher disease.

The authors propose that two critical features which favor the unique salutary effects of enzyme treatment in Gaucher disease are:

1. Apart from neuronopathic disease, the cells affected by storage are of monocyte-macrophage lineage; these infiltrate the liver, spleen, and bone marrow. Since they are of hematopoietic origin and are recruited to sites of disease, successful metabolic intervention has the potential to reverse the pathological infiltration and arrest ongoing tissue and organ damage.

2. Macrophages display surface lectin-like receptors that mediate uptake into intracellular compartments to complement the enzyme deficiency and hence effective targeting to this cell type. Glucocerebrosidase appears to be unique in its targeting to lysosome and does not follow the well-described pathway of uptake for mannose-6-phosphate-receptor first demonstrated in acid hydrolases responsible for the degradation of glycosaminoglycans (mucopolysaccharides), and defective in mucolipidosis types 2 and 3 (I-cell disease).

\section{Clinical features and natural history of disease \\ Presentation}

Type 1 Gaucher disease is characterized by variability in signs, symptoms, severity, ${ }^{24,33}$ and progression, even among siblings with the same genotype and in monozygotic twins. ${ }^{34,35}$ The age of onset also is variable and the mean severity of disease shows marked differences among different ethnic groups. In patients from Japan, China, Korea, Taiwan, and Thailand, rapidly progressive disease is more common and the frequency of severe neurological signs (leading to assignment to the neuronopathic types 2 and 3 disease categories) appears generally to reflect the different distribution and occurrence of more disabling mutations in the human GBA1 gene in these populations. ${ }^{36-38}$

The disease becomes manifest in some patients as early as the second year of life, whereas others have no clinical signs until late in adult life. In patients with one of the most common mutations (eg, N370S), the mean age of the development of recognizable symptoms is 30 years. ${ }^{39}$ However, some individuals with this genotype remain asymptomatic throughout life, thus the frequency of type 1 Gaucher disease is difficult to define.

Symptomatic patients have hepatosplenomegaly, bone disease, and bleeding. Fatigue is common and pubertal delay, with associated delay in growth, ${ }^{40}$ is a frequent and important finding in children. Bone disease is common in patients splenectomized for control of hematological disease but who have not received definitive treatment. ${ }^{25}$

\section{Individual clinical features}

Splenomegaly is the most common presenting sign of type 1 Gaucher disease. The spleen can enlarge to as much as 75 times its normal size. Hepatomegaly is almost universal, but the liver size increases relatively less than the spleen, with volumes usually between one and a half and three times that of normal. Hepatic fibrosis can occur, but hepatic failure, cirrhosis, and portal hypertension are uncommon, except in patients splenectomized in childhood. Cirrhosis in Gaucher disease tends to be associated with early splenectomy and, unless attributable to coexisting hepatitis virus infection, it is characterized by massive lobar fibrosis. ${ }^{41}$

Hepatosplenomegaly may be asymptomatic or it may be associated with early satiety and abdominal complaints 
(distension, discomfort, pain). Splenic infarction may present as acute abdominal pain or pain referred to the shoulder; pathological rupture of the spleen occurs in Gaucher disease. Patients may be diagnosed with Gaucher disease after splenectomy carried out either in the course of investigation of suspected hematological malignancy or as a result of splenic rupture. Thrombocytopenia, due to splenic pooling and marrow disease, is almost always present and the bleeding tendency may occasionally be life threatening. Anemia is frequent but is not usually as clinically significant or severe as thrombocytopenia. Leukopenia with infections due to neutropenia is rarely found in patients with access to modern health care, but it may complicate extreme hypersplenism and severe disease. In occasional patients, a tendency to bleed, particularly in the perioperative situation, may result from malfunction of platelets that are of normal or near-normal number in the circulation, because of an acquired Bernard-Soulier-like defect associated with prolonged skin bleeding time; so far, this complication appears to occur principally in patients after splenectomy. ${ }^{42}$ Platelets from patients with this defect fail to agglutinate in response to ristocetin, despite normal platelet surface glycoprotein Ib and plasma von Willebrand factor activity. The defect is attributable to a factor, not a platelet-specific antibody as in the pseudo-Bernard-Soulier condition but probably glucosylceramide or a molecular congener present in Gaucher disease plasma, which abolishes ristocetin-induced agglutination of normal donor platelets. The factor associates loosely with the platelet surface and impedes the action of the membrane glycoprotein Ib-V-IX heteromeric complex, which mediates platelet adhesion to the subendothelium and interacts with von Willebrand factor, thrombin, and fibrin.

Although it may have severe clinical consequences, the acquired Bernard-Soulier-like defect (which is ameliorated by enzyme therapy) is a rare complication of Gaucher disease. Other potentially significant qualitative platelet abnormalities appear to be more prevalent in this condition, even if they are of less certain clinical relevance. Recently, Simchen et $\mathrm{al}^{43}$ have reported a retrospective review of the outcomes of 45 pregnancies in 20 women with Gaucher disease whose platelet function had been investigated by aggregometry and cone and platelet analyses. Six of the women received treatment with enzyme during pregnancy. Fourteen out of 45 deliveries were complicated by postpartum hemorrhage, but neither thrombocytopenia nor enzyme therapy appeared to influence this complication. Twelve of the 13 women who experienced hemorrhage had impaired platelet aggregation (defined as aggregation below the third percentile of average aggregate size), compared with only two of seven nonbleeders. Since $79 \%$ of women with impaired cone and platelet aggregation had hemorrhage after at least one delivery and this was significantly greater than the $16.7 \%$ of those with normal platelet function, it appears that prevalent abnormalities as judged by these tests may be predictive for obstetric bleeding a common complication in type 1 Gaucher disease.

Pancytopenia and its attendant complications may arise in Gaucher patients after splenectomy. This usually indicates extensive long-standing disease in which the population of pathological macrophages extends centrifugally to the far reaches of the marrow compartment in the skeleton; however, in most instances, definitive enzyme augmentation rapidly corrects the associated hematopoietic failure. Rarely, pancytopenia with other characteristic features of megaloblastic change may complicate deficiency of biologically active cobalamins (vitamin $\mathrm{B}_{12}$ ), which appears to be associated with Gaucher disease. ${ }^{44,45}$

Before enzyme replacement therapy, splenectomy was often required to ameliorate dangerous hypersplenism. Splenectomy is not only associated with risks of infection but also with particular worsening of several aspects of Gaucher disease: bone disease frequently accelerates; ${ }^{25,46}$ severe liver involvement typically causes massive fibrosis, portal hypertension, and liver failure, ${ }^{41}$ lung infiltration ${ }^{47}$ with pulmonary hypertension can progress $;{ }^{48}$ and in type 3 patients, neurological disease has been reported to deteriorate after the spleen has been removed. ${ }^{47,49}$

Skeletal manifestations may be crippling and painful; they often have a large impact on activities of daily living. ${ }^{46}$ Skeletal disease is characterized by diffuse bone pain, punctuated by painful crises, often resulting in osteonecrosis (avascular necrosis) with subsequent joint collapse affecting the proximal and distal femur, proximal tibia, and proximal humerus. Osteolytic lesions, pathological fractures, vertebral compression fractures, and other fragility fractures associated with low bone mineral density occur. ${ }^{25}$

Many affected children grow poorly and have delayed puberty. However, in one series, all patients experienced spontaneous catch-up growth and over $80 \%$ achieved a final height within the expected range based upon midparental height. ${ }^{50}$ In the same group of children, puberty was delayed in almost two-thirds of 57 patients in whom primary endocrine pathology was excluded. Most children with severe growth deficiency have severe disease in the viscera. ${ }^{51}$

Interstitial lung disease is a less common manifestation of Gaucher disease. ${ }^{47}$ It occurs when Gaucher cells infiltrate 
the alveolar spaces and interstitium. Severe pulmonary hypertension occurs infrequently. ${ }^{48}$ Hepatopulmonary syndrome with dyspnea aggravated by sitting up - as a result of abnormal vascular shunting in the lungs - occurs principally in patients with severe liver disease and in whom the spleen has been removed, and it may be associated with pulmonary hypertension. ${ }^{41}$

Pregnancy and labor in Gaucher disease patients present additional risks: the pregnant state exacerbates the condition and usually leads to worsening thrombocytopenia. Osteonecrosis occurs with greater frequency in the puerperium. The position in relation to enzyme therapy during pregnancy is considered in detail later in this article; close specialist medical supervision and monitoring is advised during pregnancy, labor, and the puerperium. A review of the literature and of fresh data relating to the influence of Gaucher disease on pregnancy outcomes, the influence of pregnancy on Gaucher disease, and the experience of enzyme therapy in pregnancy ${ }^{52}$ has demonstrated an increased risk of adverse pregnancy outcomes, including postpartum hemorrhage and infection. Equally, manifestations of Gaucher disease often worsen in pregnancy, with expanding organomegaly, falling platelet counts, and an increased risk of oseonecrosis, especially in the puerperium.

Gaucher disease is associated with parkinsonian syndromes, including parkinsonism with Lewy body dementia. ${ }^{53}$ Glucocerebrosidase mutations in heterozygous as well as homozygous forms have been associated with a variety of parkinsonian phenotypes; these tend to have an earlier onset and are less responsive to dopaminergic agonists than "classical" non-Gaucher-associated Parkinson disease. ${ }^{54}$ The mechanism underlying this association is unclear, but molecular interactions between glucocerebrosidase mutants and processing of $\alpha$-synuclein are strongly implicated: $\beta$-glucocerebrosidase mutants linked to Gaucher disease, Parkinson disease, and Lewy body dementia alter $\alpha$-synuclein processing. ${ }^{55}$ Overexpression of several mutant glucocerebrosidases (including familiar Gaucher disease-related molecules such as N370S, L444P, D409H, D409V, E235A, and E340A) increased $\alpha$-synuclein expression in cultured neural cell lines, but without altering glucocerebrosidase activity; in contrast, overexpression of wild-type glucocerebrosidase significantly increased glucocerebrosidase activity, as expected, but had mixed effects on $\alpha$-synuclein. ${ }^{56}$ In cell culture models, the "gain of function" toxic effect was mitigated by rapamycin. Loss of glucocerebrosidase activity first led to neuronal ubiquitinopathy and axonal spheroids - a phenomenon that is shared with numerous other lysosomal disorders affecting the nervous system. Parkinson disease, an adult neurodegenerative disorder, has been linked clinically to Gaucher disease, but the mechanistic connection is only now becoming apparent. Mazzulli et $\mathrm{al}^{57}$ have shown that functional deficiency of glucocerebrosidase in primary cultures or human induced pluripotent stem cell neurons, caused by glucocerebrosidase mutations that are frequently found in Gaucher disease, compromises lysosomal protein degradation, causes accumulation of $\alpha$-synuclein, and induces neurotoxicity by mechanisms related to aggregation. The new concept here suggests that a positive feedback loop of reduced lysosomal function and $\alpha$-synuclein accumulation induces neurodegeneration.

Patients with acute neuronopathic Gaucher disease have been classified as type 2 Gaucher disease; there is an early onset of bulbar paresis, cranial nerve palsies, opisthotonus, spastic paresis with variable hepatosplenomegaly, and usually mild hematological abnormalities. This acute form of Gaucher disease is usually fatal before the age of 2 years, with malnutrition and aspiration pneumonia due to recurrent seizures and development of a decerebrate state. A perinatal lethal form of Gaucher disease, best classified with type 2 disease, is associated with hydrops fetalis and a defect in the ability of skin to retain moisture - "collodion baby." 58,59

Chronic forms of neuronopathic Gaucher disease are termed type 3 Gaucher disease. Operationally this may be described as progressive neuronopathic disease that is not acute and infantile in onset. In practice, type 3 disease represents a highly heterogeneous multisystem disorder including neurological deficits: it has been divided into subtypes. Type 3A Gaucher disease is characterized by progressive neurological failure in children with cognitive impairment, myoclonic or tonic-clonic epilepsy, supranuclear gaze palsies, and ataxia; hepatosplenomegaly is usually mild, but the patients succumb to progressive brainstem injury or uncontrollable seizures. Patients with type 3B Gaucher disease have static supranuclear gaze palsy, usually of horizontal but occasionally of vertical type; in contrast to type $3 \mathrm{~A}$ disease, the visceral manifestations are typically florid, with severe hepatosplenomegaly, anemia, portal hypertension, and extensive osseous manifestations including vertebral necrosis and gibbus formation at the upper thoracic level. In the untreated state, type $3 \mathrm{~B}$ patients usually die as a result of pulmonary infiltration, uncontrollable hemorrhage, or hepatic disease. ${ }^{33}$

A further unusual variant of chronic neuronopathic Gaucher disease (so-called type 3C) has so far been associated only with homozygosity for the rare missense mutation 
in the $G B A 1$ gene leading to formation of a variant $\mathrm{D} 409 \mathrm{H}$ enzyme. ${ }^{14,15,60}$ This unique disorder has been reported principally in Arab populations, but it has also been described in Spain - as well as Mexico, Turkey, Egypt, and the Middle East. There is stable oculomotor apraxia with moderate splenic enlargement, while liver enlargement and skeletal manifestations may not be prominent, but there is disease of the cardiac valves, and clinical inspection reveals bilateral corneal opacification. Cranial computed tomography scans show dilatation of the lateral ventricles with brachycephaly. The heart shows progressive thickening and calcification of mitral and aortic valves, associated with mitral regurgitation, mild aortic insufficiency, or severe aortic stenosis. Isolated reports from Japan documented the abnormality in advance of mutation analysis. ${ }^{61}$ Later studies confirmed the occurrence of homozygosity for D409H in Japanese patients with this Gaucher disease variant. ${ }^{62}$

Heavy calcification of the valve leaflets, extensive calcification of the entire aortic arch, and involvement of the coronary arteries occurs. In several cases, Gaucher cells have been demonstrated in the valvular tissue. ${ }^{63}$ Sudden death due to cardiac tachyarrhythmia before surgery for aortic valve disease has been reported, and in some cases thickening and calcification has been noted within the myocardium and the descending aorta. ${ }^{64,65}$ Type $3 \mathrm{C}$ disease resembles an intermediate syndrome between a glycosphingolipidosis and a mucopolysaccharidosis (or a glycoproteinosis), but the biochemical explanation for the clinical phenotype remains elusive; type 3C Gaucher disease responds incompletely, if at all, to enzyme therapy.

\section{Clinical course and life expectancy}

The clinical course and life expectancy of type 1 Gaucher disease is highly variable. Phenotypic expression cannot be reliably predicted by genotype, since severity may vary among siblings, even between identical twins. ${ }^{35}$ The spectrum ranges from asymptomatic disease, discovered incidentally in elderly adults, to fulminant disease presenting in early childhood. The disease is usually progressive, but the rate of progression varies. In general, the disease progresses more rapidly in those who present at a young age. ${ }^{66}$ The average life expectancy at birth for a patient with type 1 disease in the modern era was found to be 68 years, compared with 77 years in the standard US population. Splenectomized and nonsplenectomized patients had a life expectancy of 64 and 72 years, respectively. ${ }^{67}$ Symptomatic patients may die prematurely from the consequences of splenectomy, severe bone disease, bleeding, infection, liver failure, or severe pulmonary disease..$^{20,67}$ The consequential effects of Parkinson disease are also likely to account for excess deaths. In addition, patients with Gaucher disease have long been recognized to be at increased risk of hematological malignancy, especially B-cell lymphomas and multiple myeloma. ${ }^{68,69}$

\section{Outcome measures}

From the early days of its use, it rapidly became clear that many cardinal features (notably hematological, visceral, and osseous) of Gaucher disease responded to enzyme therapy; not only was the disease to a large extent reversible but also the improvements could be readily documented. Platelet counts and blood hemoglobin concentration reflect disease severity in nonsplenectomized patients; their response to treatment is easily measured by standard technology. ${ }^{70}$ The liver and spleen enlarge with progression of disease over time, and shrink on treatment. Several methods have been developed to derive volumetric measurements of liver and spleen volumes from magnetic resonance imaging and X-ray computed tomography images. ${ }^{71}$ The infiltration of bone marrow by Gaucher cells imparts a clear signature on magnetic resonance imaging of the skeleton as the normal fat signal in adult marrow is replaced by a more hydrated cellular infiltrate. ${ }^{72}$ Bone mineralization density is often reduced and salutary responses to treatment are readily documented by conventional dual energy X-ray absorptiometry. ${ }^{72-76}$ Subjective measures are also revealing; validated clinical scores of pain, fatigue, and health-related quality of life are sensitive to the evolution and amelioration of disease. ${ }^{77-79}$

Not only are the cells and tissues that are affected by other lysosomal diseases less susceptible to therapeutic augmentation than the macrophage compartment but also clinically articulate responses are not so readily monitored. Hepatosplenomegaly is a feature of mucopolysaccharidosis type 1 and decreases after treatment with enzyme therapy (laronidase [Aldurazyme ${ }^{\circledR}$; Genzyme]) but, while there might be a slight improvement in abdominal discomfort and swelling, there is little effect on a premorbid systemic inflammatory state and correction of plasma protein abnormalities with rapidly improved blood counts - as seen in Gaucher disease: the skeletal and connective tissue abnormalities, and respiratory complications, so much part of mucopolysaccharidosis type 1, are not readily ameliorated.$^{80}$ Furthermore, many patients with mucopolysaccharidosis type 1 have impaired neurological function, which is beyond correction with enzyme therapy. In several clinical trials of enzyme therapies for mucopolysaccharidoses, especially types 2 and $6,{ }^{81,82}$ a composite clinical end point has been selected: the 6-minute walk distance. 
While this provides a single generic measure of overall functioning, it is open to difficulties of interpretation (particularly in long-established disease) and is unlikely to show dramatic therapeutic responses.

Fabry disease provides another example of a disease that is challenging to monitor: here the multisystem nature of the condition, with effects on the peripheral and autonomic nerves, the heart, the skin, the kidney, and the blood vessel supply to the brain is difficult to quantify. In the untreated state, quality-of-life measures are poor ${ }^{83}$ and the uncontrolled effects of introducing a treatment under such circumstances may be reported to be positive. A strong placebo effect on symptoms was observed in one of the landmark clinical trials. ${ }^{84}$ It would be difficult to suggest that either of the enzyme treatments radically improves the disease, and a useful long-term effect is difficult to determine: renal glomerular function may show evidence of "stabilization," or inferentially a decreased rate of decline, but during the course of therapy patients may become deaf or they may spontaneously suffer a severe stroke or life-threatening cardiac arrhythmia. ${ }^{85}$

Credible outcome measures enhance the development of treatments, through easier design and implementation of and recruitment to clinical trials. But more work on the natural course of these rare diseases and innovative trial designs that examine time-to-event and other aspects of pathology, which may be predicted to respond to the intervention, is needed.

\section{Easy concepts and trials}

\section{The concept of enzyme replacement}

Once the nature of the enzyme defect in Gaucher disease was known, Brady et a ${ }^{86}$ advanced the notion of a treatment that would involve parenteral supplementation of the purified enzyme protein. Although it was not known until 1968 that $\beta$-glucocerebrosidase was a lysosomal enzyme, ${ }^{87}$ in this Brady et al ${ }^{86}$ followed the discoverer of the lysosome, Christian de Duve, ${ }^{88}$ (see also Appelmans et al ${ }^{89}$ ) who predicted that because of its central role in pinocytosis, autophagy, and phagocytosis, the lysosomal compartment in cells may be readily accessed from the extracellular space. This initially vague concept was reinforced by the demonstration by Fratantoni et $\mathrm{al}^{90}$ of cross-correction of lysosomal enzyme deficiencies that lead to impaired digestion of mucopolysaccharides in fibroblasts cultured from patients with Hurler and Hunter diseases (mucopolysaccharidosis types 1 and 2, respectively). The cross-corrective factors were quickly shown to be high-molecular-weight forms of the enzymes normally responsible for specific degradative steps that were lacking in the disease; the proteins were reciprocally secreted into the medium by nondeficient cells and were taken up from the medium by deficient cells, in which they were targeted to the lysosomal compartment and thus functionally correcting the genetic defect.

Although the lysosomal nature of $\beta$-glucocerebrosidase, which is deficient in Gaucher disease, was shown in $1968,{ }^{87}$ the glycoprotein nature of this enzyme was not at first appreciated. Studies in I-cell disease by Hickman et a ${ }^{91}$ revealed the key observation that although fibroblasts cultured from patients with I-cell disease could readily incorporate enzymes secreted by healthy fibroblasts, the enzymes secreted by I-cell fibroblasts could not be taken up by other cells. Research by Elizabeth Neufeld, William Sly, their colleagues, and other investigators showed that the corrective factors in the mucopolysaccharidoses and several other lysosomal diseases were phosphohexosyl glycoforms of the deficient enzymes in these disorders. ${ }^{92,93}$ Mannose 6-phosphate residues displayed on $\mathrm{N}$-glycans were found to be a common lysosomal protein recognition signal. Later, the groups of Stuart Kornfeld ${ }^{94}$ and Kurt Von Figura ${ }^{95}$ isolated the endo-H-sensitive $\mathrm{N}$-glycans from nascent lysosomal enzymes: these precursor molecules harbored the predicted phosphate esters on mannose groups but were blocked by outer $\alpha$-linked $N$-acetylglucosamine residues. Studies of the biosynthetic intermediates in lysosomal glycoprotein formation allowed the mechanism by which phosphomonoesters of mannose 6-phosphate are introduced into the molecules and decorate a large class of newly synthesized enzymes destined for the lysosome - and which can be delivered to the organelle from sources external to the cell by endocytosis mediated by mannose 6-phosphate receptors. ${ }^{94}$

However, while the phosphomannosyl ligand is operative for many lysosomal proteins, studies of the biosynthesis of lysosomal glucocerebrosidase have shown that it is not subject to these post-translational modifications and does not enter the lysosome through the mannose 6-phosphate receptor-mediated pathway. ${ }^{96}$ The existence of a novel chaperone molecule, the lysosomal membrane protein LIMP-2, which mediates delivery of nascent glucocerebrosidase to the organelle in many but not all tissues, has recently been identified. $^{32}$

\section{Early clinical studies}

Investigations into the use of enzyme therapy for Gaucher disease required an abundant supply of active enzyme purified from human sources. Two groups developed purification techniques with a view to therapy. Brady and colleagues (particularly Peter Pentchev) ${ }^{97}$ developed 
a purification scheme that was adapted further for largescale use by Scott Furbish (Furbish et $\mathrm{al}^{98}$ ). One of people involved in the work of Furbish et $\mathrm{al}^{98}$ was Henry E Blair of the New England Enzyme Center, based at Tufts University, Boston, and later a cofounder of the Genzyme Corporation and senior vice president of scientific affairs from 1981 to 1990. Simultaneously, Ernest Beutler (see Dale and Beutler ${ }^{99}$ and Dale et $\mathrm{al}^{100}$ ) showed that glucocerebrosidase could also be purified from placenta using acetone, without the $70 \%$ loss of enzyme activity associated with Pentchev's method, ${ }^{97}$ based on detergent extraction, and hydrophobic interaction chromatography. However, the acetone-solubilized glucocerebrosidase had an absolute requirement for acidic phospholipids for its activity. Nonetheless, the development of a large-scale modified procedure for the purification of human glucocerebrosidase with a high specific activity ( $>10^{8}$ units/mg of protein) from human placenta proved to be decisive. The method employed extraction with cholate, salt fractionation, acid precipitation, butanol extraction, and hydrophobic chromatography. ${ }^{98}$

With protein of sufficient quantity and purity, experimental studies - including preliminary clinical trials in patients with Gaucher disease - could be undertaken in earnest. A key question was whether infusion of the purified glucocerebrosidase would dispose of excess glucocerebroside. The enzyme was given intravenously into two splenectomized patients with Gaucher disease and needle biopsy samples of liver were obtained before and 24 hours after the infusion. A 15-year-old boy with type 3 Gaucher disease and glucocerebroside $0.702 \mathrm{ng} / \mathrm{g}$ wet weight of liver (a 22-fold increase) received a single infusion of $1.5 \mathrm{mg}$ ( $25 \mathrm{IU})$ of purified glucocerebrosidase $(0.47 \mathrm{IU} / \mathrm{kg})$. A 51-year-old woman with type 1 Gaucher disease and pretreatment hepatic glucocerebroside of $1.634 \mathrm{ng} / \mathrm{g}$ wet weight ( $~ 35$ times the normal value for females) also received glucocerebrosidase (3.3 mg [55 IU]) in equally divided doses on 2 consecutive days $(0.97 \mathrm{IU} / \mathrm{kg})$. Analysis of glucocerebroside in liver biopsy specimens obtained 24 hours after infusion of the enzyme revealed that there had been a $26 \%$ reduction of this lipid in the recipients and that other lipids were unchanged. The two recipients tolerated the infusions well, and neither had adverse reactions to the placental enzyme. ${ }^{97}$ Subsequent infusions of human placental glucocerebrosidase for the woman with type 1 Gaucher disease also induced no signs of sensitization. The following year, $9.3 \mathrm{mg}$ (155 IU, $2.5 \mathrm{IU} / \mathrm{kg}$ ) of glucocerebrosidase was infused into a young woman with type 1 Gaucher disease and glucocerebroside $17.9 \mathrm{ng} / \mathrm{g}$ wet weight of liver ( 400 -fold increase); however, the relative reduction was only $8 \%$, and the amount of glucocerebroside cleared from the liver per unit of enzyme activity administered was essentially the same in all three of these subjects. ${ }^{101}$

It soon was apparent that human placental glucocerebrosidase prepared by large-scale hydrophobic chromatography had inconsistent clinical effects and in experimental studies conducted with animals it was shown to have poor delivery of parenterally administered enzyme to nonparenchymal (principally Kupffer) cells in the liver. ${ }^{102}$ Given that the crude placental enzyme required delipidation by $n$-butanol treatment to ensure its affinity for the hydrophobic interaction chromatography, it seems likely that this led variably to denaturation.

A modified purification procedure for human glucocerebrosidase, taking advantage of the hydrophobicity of glucocerebrosidase, was later developed..$^{98}$ However, when the enzyme prepared by this new procedure was infused into two young males with Gaucher disease, the reduction in hepatic glucocerebroside was disappointing. ${ }^{103}$ In studies with additional patients, inconsistent reductions in hepatic glucocerebroside were observed.

Using the purified enzyme obtained from placentae, Morrone et $\mathrm{al}^{104}$ (including Pentchev) found rapid clearance from the circulation when infused into rats. Uptake was found to be dominant in hepatocytes, with significant delivery to sinusoidal cells, but included endothelial and Kupffer cells. The uptake into all liver cell types was inhibited by mannose-containing glycoproteins, even though the enzyme was unmodified and hepatocytes were not believed to express receptors for uptake of mannose-terminated glycoproteins.

Dale and Beutler ${ }^{99}$ attempted to engineer delivery to macrophages by embedding purified glucocerebrosidase in erythrocytes. A trial of this form of enzyme therapy in a single patient had marginal effects. ${ }^{105}$ The technique was further refined by coating the erythrocytes with $\gamma$-globulin to improve delivery of enzyme, through phagocytosis, to monocytes and related cells. ${ }^{106}$ As it turned out, this approach by Beutler at Scripps Clinic (La Jolla, CA) failed to generate a successful treatment and was overshadowed by findings at the NIH by Brady and colleagues.

\section{Carbohydrate remodeling}

While these preliminary clinical studies were being conducted, cognate research into the mechanisms that determined hepatic uptake of circulating glycoproteins was also bearing fruit elsewhere in the NIH with the discovery by Gilbert Ashwell and his colleague Anatol Morrell of the asialoglycoprotein receptor (see Hudgin et $\mathrm{al}^{107}$ ). 
At the time, there was an intensive research focus into the possibility of complementing lysosomal defects in inborn diseases of the lysosome by supplying corrective enzymes. As already outlined, the general stratagem of complementing lysosomal enzyme deficiencies was initiated in another laboratory at the NIH under the direction of Neufeld. ${ }^{108}$ However, the seminal discovery of the mannosebinding lectin of the macrophage by Philip Stahl et al ${ }^{109}$ at Washington University, St Louis, MI, was the critical breakthrough. This revelation focused attention on delivery of proteins to be explored for therapeutic purposes in Gaucher disease - in which the prime cellular target is the eponymous macrophage. ${ }^{110}$ In vivo and laboratory studies also carried out at this time in St Louis by William Sly and colleagues (see Achord et $\mathrm{al}^{111}$ ) with different glycoforms of acid $\beta$-glucuronidase, which is deficient in the lysosomal disease mucopolysaccharidosis type 7 (Sly disease), led to the practical realization that the mannose/lectin receptor could be utilized efficiently to target human glucocerebrosidase to macrophages in Gaucher disease after modification of its carbohydrate residues.

Once it was appreciated that human glucocerebrosidase was a glycoprotein, investigations were undertaken over several years to characterize thoroughly its carbohydrate composition and behavior. ${ }^{112}$ Carbohydrate analysis of the placental enzyme showed that the enzyme contained both high-mannose-type oligosaccharides and a series of triantennary and biantennary complex-type oligosaccharides. Complex-type oligosaccharides with incomplete outer chains were also found. This contrasts with other lysosomal enzymes such as $\beta$-glucuronidase and cathepsin D in which only highmannose-type oligosaccharides are found. Although some of the biantennary sugar chains of the glucocerebrosidase had incomplete outer chains with $N$-acetylglucosamine or mannose terminals (13\%), efficient endocytosis mediated by specific receptors for these sugars does not occur, since only weak monovalent interactions with the oligomannose chains on one of the four glycosylation sites of the enzyme are possible. Three of the side chains were of the complex oligosaccharide type - principally terminating with sialyl and galactosyl groups. When administered intravenously in living rats, up to $98 \%$ of these glycoforms of glucocerebrosidase was taken up by liver parenchymal cells - rather than the nonparenchymal cells, of which Kupffer cells (hepatic macrophages) were the desired target. ${ }^{113}$ Preferential uptake by hepatocytes can plausibly be attributed to the asialoglycoprotein receptor, which has a high affinity for galactoseterminated glycoproteins. ${ }^{114}$
The carbohydrate display on the protein was modified by sequential deglycosylation to reveal terminal mannose residues. ${ }^{115}$ At first, this apparently cumbersome enzymatic deglycosylation approach was not favored. Instead, linear pentamannosyl residues were covalently linked to glucocerebrosidase, but this chemical modification failed to enhance delivery of the glycoprotein to macrophages in experimental animals. Subsequent linking of trimannosyl-dilysyl residues to glucocerebrosidase induced a fourfold enhancement of uptake by macrophage-rich cells populations, but this was not considered to be sufficient to secure a salutary clinical effect in living patients with Gaucher disease. ${ }^{116}$ Ultimately sequential enzymatic remodeling of the native placental glucocerebrosidase was revived to generate mannoseterminated enzyme - a modification that greatly increased the delivery of glucocerebrosidase to nonparenchymal cells in rat hepatocytes. ${ }^{115}$

Sequential remodeling of the three complex $N$-linked glycosylation sites to expose the core mannose residues on human placental $\beta$-glucocerebrosidase for subsequent clinical development was achieved by serial treatment with neuraminidase, $\beta$-galactosidase, and $\beta$ - $N$-acetylglucosaminidase, using specific exoglycosidases purified from the jack bean (Canavalia ensiformis). ${ }^{117}$

The success of this stratagem was contributed to by the discoveries of Ashwell at the NIH and of Stahl and Sly and their colleagues ${ }^{107,109,111}$ at the Washington University School of Medicine, St Louis, MI; the success of the research later engaged several groups and intensified clinical investigation generally into the targeted delivery of several therapeutic enzymes to their site of action in the lysosome. ${ }^{118}$

\section{Early clinical trials and development Efficacy studies of macrophage-targeted glucocerebrosidase}

Ultimately a strong clinical programe using remodeled human placental glucocerebrosidase for Gaucher disease was advanced by Norman Barton, John Barranger working with Scott Furbish, Peter Pentchev, and Gary Murray in Dr Roscoe Brady's laboratory at the NIH. At the time, no credible or tractable animal model of Gaucher disease existed and, as a result, proof-of-concept studies for clinical application were carried out in patients. The enzymatically modified (mannoseterminated) human placental glucocerebrosidase was administered intravenously to eight patients with type 1 Gaucher disease. Approximately 190 IU of the protein were infused on a weekly basis for 6 months. A striking response was observed in a 6-year-old boy, the smallest and youngest trial participant 
and the only subject to be reported. ${ }^{1}$ After a few months of treatment at a weekly dose in the range of $12-15 \mathrm{IU} / \mathrm{kg}$ of body weight, there was a marked increase in hemoglobin concentration, from severely anemic values to a level near the healthy reference range. After 6 months of enzyme therapy, the platelet count also rose significantly. To determine beyond reasonable doubt whether these salutary changes were attributable to the intervention, the infusions were temporarily discontinued and after cessation of the infusions, the hemoglobin gradually declined to the pre-infusion concentration. The platelet count also decreased during the period without glucocerebrosidase treatment. Thereafter, infusions of macrophage-targeted human placental glucocerebrosidase were resumed with weekly administration at an augmented dose of $30 \mathrm{IU} / \mathrm{kg}$ of body weight. The hemoglobin concentration increased more rapidly than after the previous infusions at the smaller dose. ${ }^{2}$ Administration of glucocerebrosidase was continued over the next 48 months. During this interval, liver and spleen size continued to diminish (spleen decreased significantly), and there was radiological evidence of improvement in the skeleton. Given the size of this patient, the investigators eventually deduced that the reason for the spectacular response in this individual was that he received more of the enzyme on the basis of size than any other trial participant.

In the light of the promising findings in this single patient, aged 6 years (who today is married and a healthy parent), an explorative dose-response study was undertaken with determinations of hepatic glucocerebroside after single infusions of macrophage-targeted $\beta$-glucocerebrosidase at various doses. The information gained from this study led to the realization that to obtain significant clinical benefit within a 6-month period in nonsplenectomized patients with Gaucher disease, administration of 60 IU of modified glucocerebrosidase per kilogram of body weight every other week would be advisable.

The pivotal clinical trial by Norman Barton and collaborators to investigate therapeutic efficacy of mannose-terminated glucocerebrosidase enrolled just twelve patients with intact spleens and moderate to severe type 1 Gaucher disease. Each patient received $60 \mathrm{IU} / \mathrm{kg}$ of macrophage-targeted human placental glucocerebrosidase by intravenous infusion on alternate weeks. Four of the patients were adults and eight were children; there were seven females and five males in the trial. Twelve other mild type 1 Gaucher disease patients with intact spleens, and who were not treated with enzyme augmentation, were subject to parallel monitoring, but the patients were not matched by age, sex, or clinical severity of disease. Infusions of macrophage-targeted glucocerebrosidase every other week increased the hemoglobin concentration of all the trial recipients. By 6 months, the hemoglobin concentration had increased in all the patients $(P<0.003)$ After $9-12$ months of treatment, the hemoglobin concentration had risen to within the normal reference range in seven of the recipients. ${ }^{3}$

In the control (noninfused) patients, hemoglobin concentrations persistently declined. A significant increase in platelet count was noted by 6 months in seven of ten thrombocytopenic patients who received the macrophage-targeted preparation of glucocerebrosidase. In two of the twelve patients with normal platelet counts at the start of this trial, the platelets remained within the healthy reference range during the investigation. Platelet counts rose to normal in two of the recipients after 21 and 37 infusions. No patient in the group not in receipt of enzyme had an increase in platelet count. As the enzyme infusions continued, further salutary increases in the platelet count were noted. Spleen volume (a key therapeutic end point and efficacy marker) reduced by a mean of $33 \%$ (range $14 \%-75 \%$ ) in all patients after treatment for 6 months, while splenic volume increased in three of the noninfused patients over the 6-month period of observation. Hepatic volume decreased significantly in most patients receiving the enzyme but was unchanged in those who were untreated. Finally, early indications of skeletal improvement were observed in just 6 months. ${ }^{3}$ It is notable that during subsequent observations over 2 years, there was continuing evidence of disease amelioration with improved blood counts, well-being, and resolution of hepatosplenomegaly. Signs of skeletal improvement were also apparent in the young boy in the previous pilot study: replacement of the extensive infiltrate of Gaucher cells in his bone marrow with normal marrow progenitors probably accounted for the main salutary effects. ${ }^{119}$

A notable feature of these early trials was the absence of untoward side effects or adverse reactions; during the pivotal clinical efficacy study, the treatment induced no antibody responses to the exogenous glucocerebrosidase. ${ }^{120}$ Later, in a larger cohort of patients treated repeatedly with macrophagetargeted glucocerebrosidase (alglucerase [Ceredase]), 15\% developed IgG antibodies to this preparation. Notwithstanding the emergence of the antibody response, the efficacy of the enzyme appeared to be unimpaired, and unwanted clinical effects proved to be scarce. ${ }^{121}$

The clinical efficacy of enzyme therapy using human placental glucocerebrosidase modified to reveal terminal mannose residues by sequential deglycosylation in patients with type 1 Gaucher disease was promptly confirmed by other investigators. ${ }^{122-124}$ 
Given the contemporary regulatory environment and justified alarm about transmission of hepatitis viruses $\mathrm{B}$ and $\mathrm{C}$ from human-derived blood coagulation products in hemophilia syndromes, as well as cases of new variant Creutzfeldt-Jakob disease resulting from the administration of growth hormone extracted from pooled human pituitary tissue, it is remarkable that Genzyme, the NIH, and the Gaucher community were not part of a similar catastrophe. In fact, given the unprecedented international scale of the operation to obtain the starting material, involving thousands of metric tons of human placentae worldwide, the largely untrammeled success of Ceredase is little short of miraculous. With a small yield, to obtain sufficient protein to treat an adult with Gaucher disease required several hundred metric tons of placentae each year. At the height of the manufacturing effort for Ceredase, placentae from about one-third of the world's births found their way to the tissue banks of the Pasteur Mérieux of Lyon, France (pers comm; Alan Smith, Cambridge, UK, 2006). Pasteur Mérieux (a subsidiary of Rhône-Poulenc at the time) extracted human immunoglobulin from the tissue, after which the residue was obtained by Genzyme for entry into a multistep extraction procedure, followed by exposure to the three exoglycosidases to remodel the protein for the manufacture of alglucerase (Ceredase). In fact, the French vaccines and blood products group suspended the distribution of several immunoglobulin products used in the treatment of allergy, hepatitis, and immunoglobulin deficiency in France in 1992, following recommendations of the Ministry of Health in relation to hepatitis $\mathrm{C}$ virus infection.

Clearly in this context there was an immense incentive for Genzyme to develop a potentially safer, genetically engineered product with consistent quality control and availability of supply. Treatment (and the supply) of modified human placental glucocerebrosidase was maintained over several years until a successor, the recombinant product (imiglucerase [Cerezyme]) obtained from genetically engineered Chinese hamster ovary cells, was developed intramurally and approved for and introduced to the international market in 1995.

Recombinant human glucocerebrosidase expressed in genetically engineered Chinese hamster ovary cells and then remodeled to display terminal mannose residues by sequential treatment with plant exoglycosidases has been shown to be as effective as the macrophage-targeted placental enzyme in clinical trials. ${ }^{125}$ Studies using carrier-free ${ }^{123}$ I-radio-labeled human preparations of placental glucocerebrosidase and the recombinant protein obtained from Chinese hamster ovary cell lines in patients with Gaucher disease showed striking uptake and distribution of these protein preparations to the macrophage-rich viscera and bone marrow. ${ }^{126}$ In effect the plasma disappearance of the isotope and its uptake in the affected viscera and bone marrow was rapid, but the remodeled enzymes appeared to dwell within affected visceral organs over several days. No significant difference in the pharmacodynamics and in vivo targeting behavior of these modified proteins was identified (alglucerase and imiglucerase, respectively). The two mannose-terminated preparations were also later shown to have similar pharmacological characteristics in normal mice. ${ }^{127}$

Natural human $\beta$-glucosylceramidase (glucocerebrosidase) has four glycosylation sites and 22 lysine residues, but the recombinantly produced enzyme (imiglucerase [Cerezyme]) differs slightly from placental enzyme (alglucerase [Ceredase]) according to the amino acid sequence at position 495, where an arginine has been replaced by a histidine. This amino acid change appears to have little effect on activity and biological behavior. The oligosaccharide composition differs between the recombinant and the placental enzymes: alglucerase has more fucose and $\mathrm{N}$-acetylglucosamine residues, while imiglucerase retains one high-mannose chain. As has been explained, both preparations are treated sequentially with three different exoglycosidases (neuraminidase, $\beta$-galactosidase, and $\beta-N$ acetylglucosaminidase) to expose terminal mannoses, which facilitates targeting and uptake by cells of the mononuclearphagocyte system. A pharmaceutical preparation of the recombinantly produced enzyme is described by Genzyme in United States patent No 5,549,892.

\section{Clinical development program Production of modified human placental $\beta$-glucocerebrosidase (alglucerase) for clinical use}

Ceredase and, later, Cerezyme were not only effective and safe drugs but also they were a striking commercial success. Genzyme created a unique market by forging careful relationships between treating physicians and patients, and often through supporting patient organizations financially and with setup assistance. The pivotal trial of alglucerase paved the way since most of the funds were not from the company: support came for the developmental and trial costs from the NIH and in the form of a substantial donation ( $\$ 3$ million) from the National Gaucher Foundation - the premier Gaucher charity in the United States. Genzyme has 
continued to interact profitably with its partners and patient organizations and supports single meetings with narrow subject areas (such as Gaucher disease) of which it has been the sole sponsor or organizer.

The company took the excellent opportunities for protocol advice, prelicensing concessions, and marketing exclusivity offered by the orphan medicinal product legislation in the United States, Australia, and Japan - and latterly, on its inception in Europe after 2000, for Cerezyme in type 3 Gaucher disease.

The successful education and reimbursement programs set up by Genzyme allowed the company to rise to the highest positions in the orphan drug market. This position was maintained through Gaucher disease until 2009, when the misfortunes that struck the company and its reputation led to market loss in the face of emerging biologic competitors.

\section{Early questions of cost}

The placenta-derived product alglucerase (Ceredase) clearly required massive investment in harvesting and transport of placentae, industrial scale purification of the enzyme, and carbohydrate remodeling. The annual requirement for placentae for each patient's treatment amounted to about 50,000 individual placentae (10-12 metric tons), depending on dose. ${ }^{125}$ Treatment for a thousand patients overall required about 50 million placentae, plus the means to harvest, store, transport, and process them. The cost of Ceredase was many times greater than that of other medications. Funding authorities in many countries were either unable to support its use or required onerous case-by-case application.

As the drug was priced per unit of enzyme activity, the question of cost soon became partly a question of dose. Two approaches emerged. As the initial clinical trial had demonstrated effectiveness at a dose of $60 \mathrm{U} / \mathrm{kg}$ of body weight every other week, this was the dose recommended in the summary of product characteristics. Many physicians, particularly in countries where funding allowed it, followed this guidance. In countries where funding was more difficult, physicians were often led by the arguments of Beutler, that on pharmacokinetic and pharmacodynamic grounds, lower but more frequent doses - 2-3 U/kg two to three times per week - would be equally effective. Many clinical reports and case series attested to improvements in hematological parameters and organ size with the low-dose regimen. ${ }^{128,129}$ Discussions between the two approaches were often heated. ${ }^{130,131}$

Barton et $\mathrm{al}^{1,2}$ reported different rates of response in a single child when treated with initially lower- ${ }^{1}$ and later, higher-dosage $^{2}$ regimens. Several developments have allowed a synthesis of the two approaches. The availability of informative and responsive disease markers permitted adjustment of dose, up if required or down as tolerated. ${ }^{132}$ The general acceptance of published therapeutic goals of treatment, based on realistically achievable outcomes ${ }^{133,134}$ allowed physicians to aim for agreed outcomes for the patient, adjusting the dose if needed to achieve these goals. Studies based on registry data have examined the dose-response relationship, establishing fairly conclusively that a dose-response relationship exists within the range of commonly prescribed doses. ${ }^{135}$ The argument has now shifted from whether there is a dose-response relationship to questions as to whether any benefits of increased dose are clinically useful or cost-effective.

The cost of the recombinant product Cerezyme was set in most regions to be the same as that of Ceredase. The arguments justifying the expense of the treatment may have emphasized the cost of production in early years, but they have more recently been based on the rarity of the condition and the requirement to support the development costs of the treatment, costs that are arguably similar to the costs of developing a treatment for a common disease. The cost of the treatment has captivated the interest of health economists. Despite the clearly life-transforming nature of the enzyme therapy for many patients, estimates of the cost-effectiveness of the medication, based on generally used techniques such as the quality-adjusted life year, have indicated that the cost of imiglucerase per unit of health gain greatly exceeds the thresholds commonly used to determine whether a treatment is economic. ${ }^{136,137}$ The counterargument is based on the inevitability that treatments for rare diseases will be costly and that there is a societal duty to care for individuals with rare diseases who would otherwise never have access to specific treatments. ${ }^{138}$

\section{Development of the recombinant product}

The genetically engineered human enzyme variant imiglucerase (Cerezyme) is expressed in mutant Chinese hamster ovary cells of a strain such as Lec1, in which recombinant glycoproteins are synthesized with $N$-glycans with mannose residues present at all $N$-glycan sites. The United States patent numbers that protect this product are 5,236,838 and 5,549,892.

Purified imiglucerase is a monomeric glycoprotein of 497 amino acids, containing four $N$-linked glycosylation sites $(\mathrm{Mr}=60,430)$ : it differs from placental glucocerebrosidase by one amino acid at position 495, where histidine is substituted for arginine (H495R). The oligosaccharide chains at the glycosylation sites have been modified to terminate in mannose sugars. The modified carbohydrate structures on imiglucerase 
are modified in vitro and differ slightly from those on placental glucocerebrosidase. Unlike alglucerase, which was supplied as a protein solution containing a mild solubilizing agent and was partially contaminated by proteins such as human chorionic gonadotrophin, Cerezyme is supplied as a pure lyophilized product and is reconstituted in water for clinical use.

\section{Clinical outcomes}

\section{Clinical trials of alglucerase}

As already described in detail, the first clinical trial was published by Barton et al. ${ }^{3}$ This was an uncontrolled study in twelve patients (four adults and eight children), on a dose of $60 \mathrm{U} / \mathrm{kg}$ every other week of the macrophage-targeted, placentally derived enzyme over a period of 9-12 months. The treatment received approval for marketing authorization as Ceredase by the US Food and Drug Administration (FDA) in the same year. It is of interest to compare the trial design that was sufficient to permit approval for the marketing of Ceredase in 1991 with the more onerous requirements placed upon companies bringing ultra-orphan products to market more recently. While the burden of proof required to meet FDA and European Medicines Agency (EMA) standards has increased with the growing acceptance of the dogma of "evidence-based medicine," and the consequent demand for double-blind, placebo-controlled trials in patients naïve to therapy and crossover trials in patients already on established treatments, it can still be argued that the simple open-label design of the original alglucerase trial was sufficient, given the striking and self-evident efficacy on the primary focus of the disease (splenic enlargement with hypersplenism).

\section{Clinical trials of imiglucerase}

A randomized clinical trial comparing the placenta-derived Ceredase with the recombinant Cerezyme was reported by Grabowski et al ${ }^{125}$ in 1995 . Fifteen patients with type 1 disease, naïve to specific therapy, were randomized to each treatment. The response in terms of organ volumes, hematologic parameters, and biomarkers (angiotensin-converting enzyme inhibitors and acid phosphatase activities) were not significantly different. As a result of this trial, the treatments were regarded as equivalent. The prevalence of antibody responses was greater in the case of the Ceredase-treated patients (40\% versus $20 \%$ ).

\section{Therapeutic targeting of human glucocerebrosidase in vivo}

Selectivity of mannose-terminated human glucocerebrosidase for macrophages in target organs was later explored in living patients with Gaucher disease in a $\gamma$-scintigraphic study carried out in eight subjects by Pramod Mistry and colleagues in the senior author's laboratory, Cambridge, UK. ${ }^{126}$ Human placental and recombinant preparations (alglucerase and imiglucerase) behaved identically in these studies. The emission of medium-energy (159 keV) $\gamma$-rays from this relatively short-lived isotope is well suited for wholebody $\gamma$-scintigraphy; moreover, use of the mild and indirect Bolton-Hunter labeling technique maintained the functional and enzymatic integrity of the carrier-free pure proteins.

The plasma half-life of tracer doses $(\sim 0.25 \mathrm{mg}[8 \mathrm{U}])$, carrier-free human $\beta$-glucocerebrosidase was very short, with a mean of $4.7 \pm 1$ minutes and brisk uptake into the liver (34\%), spleen (16\%), and affected bone marrow lesions; splenic uptake ranged from only $2.7 \%$ in a healthy control subject but was $30 \%$ of the administered dose in a patient with massive $\left(>3 \mathrm{~kg}\right.$ ) splenomegaly. ${ }^{126}$ The distribution corresponds to the predicted population of macrophages in these organs and demonstrates the presence of a high avidity system in vivo. Tissue uptake was saturable, so that the clearance from the circulation increased from 4.5 to 12 minutes at a repeat dose of $80 \mathrm{mg}(2800 \mathrm{U} ; 35 \mathrm{U} / \mathrm{kg} ; 1 \mathrm{mg} / \mathrm{kg}$ body weight) in one subject with Gaucher disease: exponential loss of enzymatic activity and tracer from the plasma compartment declined in parallel for 40 minutes, indicating the protein ligand remained intact in the circulation. Clearance of the label from the tissues, as judged scintigraphically, was biphasic: about onehalf disappeared rapidly with a half-life of 1.4-1.8 hours; the slower component had a half-life of 34-42 hours.

An enriched population of Gaucher cells was isolated from the spleens of two patients treated surgically for intractable hypersplenism; in one patient, a few hours after administration of $11.4 \mathrm{mg}(5 \mathrm{U} / \mathrm{kg})$ therapeutic enzyme, acid $\beta$-glucosidase activity was restored to a mean of $7.2 \mathrm{nmol} / \mathrm{h} / \mathrm{mg}$ protein (within the reference range for monocyte-derived human macrophages, $9.2 \pm 2.4 \mathrm{nmol} / \mathrm{h} / \mathrm{mg}$ protein; this was unlike the splenic Gaucher cells identically prepared from a patient who did not receive enzyme treatment immediately before surgery $(0.29 \mathrm{nmol} / \mathrm{h} / \mathrm{mg}$ protein $)$. Acid $\beta$-glucosidase activity in a splenic homogenate prepared from a patient splenectomized for hemolytic anemia due to pyruvate kinase deficiency was $2.31 \mathrm{nmol} / \mathrm{h} / \mathrm{mg}$. Appreciable targeting of the pathological macrophages in the spleen was confirmed by showing that while the $\sim 25$-fold enrichment of enzyme activity occurred in the Gaucher cells, activity in the whole splenic homogenate prepared from this patient was enriched only twofold. These studies demonstrated avid and saturable uptake of mannose-terminated human 
$\beta$-glucocerebrosidase by macrophages in vivo and they provide confirmatory basis for therapeutic enzyme targeting in living patients with Gaucher disease. ${ }^{126}$

\section{Further clinical research}

Clinical investigations have focused on (1) determining the minimum amount of enzyme required to bring about a clinical response; (2) determining the minimum quantity of enzyme necessary to maintain patients in good health once they have responded to treatment; (3) the best stratagem to establish the greatest long-term therapeutic benefit; (4) determining the optimum frequency of administration of enzyme; (5) examining the effects of enzyme replacement therapy in patients with type 3 Gaucher (chronic neuronopathic) disease; and (6) the long-term outcomes of the disease in its treated state.

\section{Registry data}

The International Collaborative Gaucher Group Gaucher Registry - commonly referred to as the Gaucher Registry - has been in operation since 1991 with a remit to collect data on safety and clinical outcomes of patients on enzyme replacement therapy. The Genzyme Corporation supports the registry with funding for a permanent administrative staff and statistical support. A panel of practicing physicians, experienced in the field, provides independent oversight and governance. The registry is open to patients who are not on specific treatments and to patients receiving medication produced by other companies.

Publications from the registry have contributed to the knowledge of the range of clinical features of Gaucher disease, the mutations in the GBA gene associated with disease, and the therapeutic effects of enzyme supplementation. The process of contributing to this collaborative project has, in the authors' view, brought physicians with differing views on the condition together and has in an indirect way helped consolidate the position of the Genzyme company as a dominant force in the Gaucher disease field.

The registry holds data on about 6500 patients at the time of writing. Although the data for individual patients are often incomplete, the number of patients involved permits analysis that would be difficult to achieve in any other way.

Treatment response has been analyzed for subgroups of patients. The pediatric data have shown the expected improvements in hematological parameters and organ volumes, but they have also shown dramatic catch-up growth $^{75}$ and achievement of normal peak bone mass. Using data obtained from the international Gaucher disease registry - initiated and supported by Genzyme - Charrow et $\mathrm{al}^{139}$ have shown a dramatic reduction in the incidence of the typical bone crises after starting enzyme therapy.

Sophisticated statistical modeling can partly compensate for missing data and can to a certain extent control for the kind of systematic bias that can occur in voluntary registry studies. An instructive example of a study employing these methods involved the assessment of dose-response relationships in registry patients. ${ }^{135} \mathrm{~A}$ system known as propensity scoring was used to determine the predictors of prescribed dose of Cerezyme in the registry. This was then used to match groups of patients who shared the propensity score or, in other words, those who shared the factors that are associated with dose, but in fact differed in the actual dose used. About 120 patients, all of who had relatively complete longitudinal data and who did not differ in parameters of disease severity, were allocated to one of three dose groups. Patients receiving the higher doses showed earlier and more complete response to therapy in platelet count, hemoglobin concentration, and splenic and hepatic volumes. The study design addressed the principle bias that had confounded earlier attempts: that patients with more severe disease may respond more in relative terms, regardless of dose, but may be allocated a higher dose because of the severity of their disease.

\section{Enzyme therapy in pregnancy}

Enzyme therapy during pregnancy is associated with a reduction in incidence of bone complications, spontaneous abortion, and bleeding episodes. No treatment-related adverse effects on the fetus or neonate have been reported..$^{52}$ In recent years, despite the usual and understandable reluctance to prescribe during pregnancy, the climate of opinion has shifted towards active treatment with enzyme therapy throughout pregnancy, particularly in women receiving therapy before conception. Clearly, this remains a matter for individual discussion between the patient and her physician.

\section{The therapeutic position Safety}

Antibody responses to the placental enzyme therapy occurred in about $13 \%$ of patients. ${ }^{121}$ Of 262 patients studied, an immunologic response was confirmed in 32 individuals. Symptoms suggestive of immediate hypersensitivity were reported in 14 of the 262 patients, but nine of these exhibited an IgG response, and none demonstrated a specific IgE response. Starzyk et al ${ }^{140}$ published a report on the pharmacovigilance data collected by the Genzyme Corporation between 1994 and 2004 that related to imiglucerase. IgG antibody responses 
were detected in $15 \%$ of patients. Adverse events that were considered related to the medication included pyrexia, chills, pruritus, rashes, urticaria, and dyspnea associated with infusions. These were generally infrequent, mild to moderate in intensity, and self-limiting. Only three patients needed to discontinue therapy as a result of infusion reactions.

\section{Supportive treatments}

Palliative and supportive treatment remains necessary, especially for patients who do not have access to treatment or for whom treatment was available late in the evolution of their disease. The neurological features continue to evade specific treatment.

Bone disease is the major cause of morbidity ${ }^{25}$ and orthopedic procedures are frequently needed, including primary joint replacement and revision joint replacement in this relatively young group of patients. A proportion of patients have undergone multiple joint replacements at several sites. Osteotomy of the femoral neck and the acetabulum has been used in young patients to realign the hip joint following osteonecrosis. Spinal corrective surgery in patients who develop kyphoscoliosis may be so severe as to require insertion of metal Harrington rods, usually in the context of type 3 disease.

Bisphosphonates have a role in the supportive management of Gaucher disease affecting the skeleton. ${ }^{141}$ There is evidence that enzyme therapy improves osteopenia, although the response may not be evident for several years. Oral bisphosphonate medication can increase bone mineral density in patients already on enzyme therapy. ${ }^{142}$ The effect of enzyme treatment on osteopenia may, in addition, be age dependent ${ }^{143}$ and osteopenia may transiently worsen after initiation of treatment as normal hematopoietic marrow replaces marrow containing pathological macrophages and accompanying cells. ${ }^{144}$ Antiresorptive therapy with oral bisphosphonates in high doses rapidly increases bone density in Gaucher disease patients who are simultaneously treated with enzyme infusions, ${ }^{142}$ but the effect of bisphosphonate treatment on bone strength ${ }^{145}$ or fracture risk is unknown.

While parenteral administration of more potent bisphosphonates (eg, pamidronate) may ameliorate Gaucher bone pain and skeletal disease in children, ${ }^{146}$ except in children or young adults with vertebral collapse and recurrent pathological fractures due to severe osteoporosis, ${ }^{147}$ there is insufficient evidence to recommend general use of adjunctive bisphosphonates in Gaucher disease. Osteonecrosis of the jaw has yet to be reported in Gaucher patients receiving potent bisphosphonates.
Gallbladder surgery is very frequently necessary in adults with Gaucher disease, in whom the frequency of cholelithiasis exceeds the high background rate in a matched but otherwise healthy population. First reported by Rosenbaum and Sidransky, ${ }^{148}$ others have shown that Gaucher patients commonly have symptomatic gallstones, and that the bile composition in Gaucher disease is abnormal, with lithogenic properties that predispose to the formation of cholesterolrich calculi. ${ }^{149}$

Liver transplantation has occasionally been required to rescue patients from end-stage liver failure or hepatopulmonary syndrome. Specialized medical treatment with pulmonary arterial vasodilators is occasionally required to ameliorate pulmonary hypertension, which is associated with splenectomy and cirrhosis; it may also follow hepatopulmonary syndrome in which high-dose enzyme therapy has, in some cases, been reported to be beneficial. ${ }^{150}$

Excessive operative bleeding as a result of thrombocytopenia, coagulopathy, or platelet function defects commonly complicates surgical intervention. The authors advise that Gaucher patients, particularly those who are asplenic, should have platelet function tests carried out before elective surgery. Postoperative sepsis, particularly osteomyelitis, is an additional concern. Close liaison between the surgeon and medical specialists familiar with Gaucher disease is strongly advised.

\section{Alternative products \\ Context}

Imiglucerase has proved to be a highly successful drug for the treatment of adults and children with Gaucher disease - including patients with the chronic neuronopathic type 3 variant, in whom it improves quality of life, hematological manifestations, and visceromegaly. The hematological and inflammatory manifestations of Gaucher disease are thus reversible, but skeletal collapse, necrotic tissue injury with fibrosis, and cell death are challenges that mandate the need for access to treatment as early as possible; issues concerning access also apply to foci of disease within the individual patient, particularly in the nervous system and skeleton, which hitherto have proved refractory to therapy. Some patients receiving full doses of imiglucerase for many years have persistent symptoms and recurrent disability due to focal disease at sanctuary sites within the viscera and bone marrow; the blood-brain barrier is a major obstacle to the treatment of the neurological manifestations.

Enzyme therapy also has disadvantages: manufacture is costly and intravenous infusions are inconvenient to 
administer. Infusions of drug, usually given every 2-4 weeks, may be painful for some patients and they may render patients unnecessarily dependent on hospital services; young children may develop a fear of needles and an aversion to the treatment. In countries with underdeveloped systems of health care, intravenous infusion may constitute an elaborate procedure, particularly in those where clean needles and appropriate equipment for administration of the drug under safe circumstances in public health services are not easily available.

These factors represent a genuine unmet medical need and in an attempt to develop the therapeutic arena, companies have investigated nonbiologic agents for the treatment of Gaucher disease, with a competitive emphasis on orally active molecules. Ultimately, therapeutic compounds that are able safely to enter the brain and nervous system by traversing the blood-brain barrier will offer immense benefit and will revolutionize the field.

\section{Miglustat}

The first alternative product to be approved (in 2002) for Gaucher disease was the iminosugar miglustat (Zavesca ${ }^{\circledR}$; Actelion, Basel, Switzerland). In the principal phase 3 trial $^{151}$ therapeutic benefit was seen in liver and spleen volume and in platelet count; in those patients with anemia at entry, salutary responses in hemoglobin concentration occurred. The effect size was less than one would normally predict for untreated adult patients with nonsevere Gaucher disease receiving enzyme treatment, but sustained therapeutic effects were observed in a follow-up study in 18 of 22 eligible patients taking the agent for up to 3 years. ${ }^{152}$

Adverse effects are common. Diarrhea and weight loss can be addressed by dietary modification and can result from inhibition of intestinal disaccharidases. Tremor is also frequent, but rarely disabling; in most patients it has resolved spontaneously. Several cases of peripheral neuropathy have been described in the literature ${ }^{151}$ and reported in the safety registry associated with this medicine. A European consensus statement, recognizing that both imiglucerase and miglustat were licensed for the treatment of Gaucher disease, reviewed their therapeutic status and developed consensus guidelines for the use of this oral agent as a second-line agent in patients with mild to moderate Gaucher disease who are unable or unwilling to take enzyme therapy. The agent affects male fertility in mice and although no genotoxicity has been demonstrated, miglustat should not be taken by patients in the reproductive age group. Miglustat is not licensed for use in children. ${ }^{153}$ The results of a 2-year prospective, open-label noninferiority study to evaluate miglustat as a maintenance treatment in adult patients with type 1 Gaucher disease who have had their disease controlled by imiglucerase are shortly to be published.

\section{Velaglucerase}

Velaglucerase alfa (VPRIV) was licensed in 2010 on the basis of an extensive clinical trial program. This protein is produced by specific gene activation in a cell line derived from a human fibrosarcoma; unlike imiglucerase, but like alglucerase, the protein has the wild-type human glucocerebrosidase sequence of amino acids and is decorated by mannose residues. The glycosylation is modified during the cell culture by the use of kifunensine, a potent and selective inhibitor of the glycoprotein processing mannosidase 1 . As a result, there is a complete shift in the structure of the $N$-linked oligosaccharides from complex chains to immature highly mannosylated structures, so that the therapeutic protein obtained from the fibrosarcoma cells does not require further modification to remodel its carbohydrate signal for macrophage uptake because it displays an extensive array of terminal mannose sugars. Claims have been made for greater cellular uptake as a result of greater mannose display, ${ }^{154}$ but these have also been disputed. ${ }^{155}$ In clinical use, the therapeutic effect appears to be equivalent to imiglucerase at the doses commonly used and using the usual end points of organ volumes, platelet count, hemoglobin, and biomarkers. ${ }^{156-158}$ Claims are also made for reduced immunogenicity, but this requires independent analytical verification and clinical assessment.

\section{Taliglucerase}

A further enzyme preparation, taliglucerase alfa, is in late clinical development and is under review by the FDA and EMA at the time of writing. It is produced by conventional recombinant technology, but in plant (carrot) cells in culture in disposable plastic containers. The amino acid sequence is modified at the $\mathrm{N}$ - and $\mathrm{C}$-termini to add short tags of 3 and 7 amino acids, respectively, which target the protein to the vacuole of the cell to aid harvesting. The recombinant plant-derived enzyme is targeted to the storage vacuoles, using a plant-specific C-terminal sorting signal, the recombinant human glucocerebrosidase expressed in the carrot cells displays terminal mannose residues on its complex glycans, presumably as a result of the activity of a plant vacuolar enzyme that modifies complex glycans. The manufacturers claim greater uptake into macrophages ${ }^{159}$ than Cerezyme, although researchers at Genzyme reported that human $\beta$-glucosylceramidase molecules with different oligomannose chain length had paradoxical effects on 
macrophage uptake ${ }^{155}$ - it was found the presence of more than two mannose residues impaired the rate of uptake. Moreover, large mannosylated structures with a mean number of mannose residues exceeding the mean of 14 per molecule reported in imiglucerase had increased affinity for the mannose-binding lectin in serum - a humoral component of the innate immune system. Taliglucerase also harbors sequences of pentose and hexose sugars such as xylose and fucose, which do not typically occur in mammalian glycoproteins but enable the protein to be secreted from the vacuolar pathway in plant cells. Despite these differences, the expression and production system does not encounter the regulatory hurdles associated with bioreactor-based systems requiring revalidation with every change to a larger bioreactor. Thus the manufacturing platform is inherently flexible and has the potential to respond rapidly to increased demands for production.

Safety studies and phase 1 trial results have not revealed any early safety concerns. ${ }^{160}$ Recent data from a pivotal phase 3 clinical trial suggest similar efficacy to imiglucerase in the doses used and over the period of the trial. Twenty-nine patients completed the protocol over 20 months with no serious adverse events; two patients developed non-neutralizing IgG antibodies; and two others developed hypersensitivity reactions. Statistically significant spleen reduction was achieved at 9 months in two dose regimens (both $P<0.0001$ ) and in all secondary efficacy end-point measures, except platelet counts at the lower dose. ${ }^{161}$ To date, no clear evidence of increased immunogenicity has emerged, despite the difference in amino acid sequence and variant glycan structures that reflect the requirements for secretion by plant cell systems.

\section{Eliglustat tartrate}

Eliglustat tartrate is another orally active inhibitor of uridine diphosphate glucosylceramide synthetase (uridine diphosphate-glucose: $N$-acylsphingosine transferase), the enzyme which catalyzes the first committed step in the biosynthesis of glycosphingolipids that are derived from $\beta$-glucosylceramide (glucocerebroside). Eliglustat is currently under late-stage clinical development for Gaucher disease by the Genzyme Corporation. The compound is one of a series of ceramide analogues that inhibit glucocerebroside synthase and were originally based on 1-phenyl-2-decanoylamino3-morpholino-1-propanol and its congeners. ${ }^{162,163}$ These molecules mimic the transition state of the enzyme and are highly potent and selective inhibitors $(\mathrm{Ki} \approx 25 \mathrm{nmol} / \mathrm{L}) .{ }^{164}$ However, it was found that the original structures have dual activity towards glucocerebroside synthase as well as
1-O-acylceramide synthase; they are toxic in cell cultures and this was attributable to increased intracellular ceramide concentrations and inhibition of cell growth. The scaffold was thus refined to increase potency for inhibiting formation of glucosylceramide while reducing the inhibitory effect on 1-O-acylceramide synthase, which leads to increased steadystate levels of intracellular ceramide. ${ }^{165,166}$

In healthy volunteers, plasma glucocerebroside concentrations diminished rapidly after dosing with eliglustat tartrate. ${ }^{167}$ In phase 2 clinical trials in patients with type 1 (non-neuronopathic) Gaucher disease, twice-daily oral administration had salutary effects on blood counts, and spleen and liver volumes were consistently reduced. ${ }^{168}$ Phase 2 clinical trial data showing continuing efficacy are currently available from patients receiving the agent for over 3 years. Investigators with experience in the treatment of Gaucher disease consider that the therapeutic activity on the hematological and visceral manifestations compares favorably with that of licensed doses of imiglucerase ${ }^{157,169}$ and velaglucerase. Moreover, in the trial data currently released into the public domain, the majority of patients have shown improved bone mineral density, correction of the pathological "dark" signal on T1-weighted magnetic resonance imaging of bone marrow, and normalization of plasma glucocerebroside and ganglioside GM3 concentrations. The drug is well tolerated and appears so far to have few unwanted effects; it shows a wide therapeutic ratio $(>30)$. Very high plasma concentrations $(>250 \mathrm{ng} / \mathrm{mL})$ of eliglustat tartrate are associated with prolongation of the $\mathrm{QT}_{\mathrm{c}}$ interval on electrocardiography and the potential for ventricular or supraventricular tachyarrhythmia. The principal route for metabolism involves CYP2D6 with minor contributions from the CYP3A4 isozyme; there is considerable population variation in the metabolism, suggesting that prudent monitoring would be advisable for patients taking eliglustat tartrate, especially those taking other agents that interact with the CYP2D6 system. Such drugs are numerous and include paroxetine, ketoconazole, and rifampicin. ${ }^{166}$

Provided the long-term safety and monitoring profile of eliglustat tartrate remains secure, there is little doubt that orally active eliglustat tartrate, which has a potent inhibitory action on the primary identified molecular target for type 1 Gaucher disease and other glycosphingolipidoses, will fulfill high expectations for clinical efficacy and use in adults with the disorder. The appropriate use of this novel oral agent in the context of its therapeutic profile and age range of patients remains a matter for discussion, but with unknown reproductive effects, it seems likely that its use in young 
persons will be restricted. With the recommendation for initial pharmacokinetic evaluation to ensure that appropriate plasma concentrations are established, it seems likely that, if eliglustat is approved for marketing (as it is expected to be), it will find its use within the context of centers with specialist experience of Gaucher disease.

\section{Access to treatment}

As capitalist economies reward perceived value, they should aspire to reward the value that the perception of health $-\mathrm{a}$ common human necessity - brings to members of the electorate. In most developed companies, it has long been recognized that the unregulated pursuit of profit without social investment is schismatic and necessarily short-lived. Moreover, capitalism can be legitimized by taxation directed to key aspects of health care: diagnostic services, medicines provision, and public health measures.

The introduction of orphan drug legislation has ensured that patients with rare diseases now receive more welcome attention through the agency of orphan drug legislation, and in many cases gain real benefit as a result of pioneering humane initiatives. However, the exception of Gaucher disease makes for bad law; the current model will need reviewing if it is to deliver value across the thousands of individually rare diseases in whole populations.

With the need to overcome numerous scientific and real-life clinical obstacles, unusual levels of motivation are needed to develop orphan or ultra-orphan agents, and beyond mandatory pharmacovigilance monitoring and fulfillment of postlicensing commitments, there is little incentive for the victorious company to invest further. In essence, orphan drug legislation is attractive because it is tantalizingly anticompetitive. ${ }^{170}$ In the ordinary course of events biotechnology companies come to believe that therapeutic research must be retransferred to the academic quarters from which, in most cases, it has emerged. Indeed, often for such investment to occur, unpredicted competition and the fear of loss of commercial primacy need to be felt. Now, with the recognition of vesivirus, the survival of any given biologic, including therapeutic enzymes, has been unexpectedly called into question: all now appreciate that there can be no immunity from unexpected manufacturing disasters.

\section{Evolution of the Genzyme Corporation in brief}

Since 1981, Genzyme grew from a small start-up company with a principal focus on Gaucher disease and other rare disorders to become a diversified business with more than 12,000 employees worldwide and 2009 revenues of $\$ 4.5$ billion; Genzyme became the world's third-largest biopharmaceutical company. Product diversification and development of diagnostic and other services later extended to kidney disease, orthopedics, cancer, transplantation, and immune disease, as well as diagnostic testing.

\section{Manufacturing difficulties and supply failure}

In June 2009, a vesivirus (strain 2117) infection occurred in the dedicated bioreactor plant at the principal production facility of the Genzyme Corporation in Allston, MA. Although vesiviruses - members of the Caliciviridae family - have not been shown to cause human disease or infection, the organism is known to interfere with the growth of Chinese hamster ovary cells used in culture to produce recombinant proteins. The vesiviral genome contains a single linear positive-sense, single-stranded RNA molecule of 7700 nucleotides. At the Allston facility, company scientists detected the virus in a highly specific assay developed after standard tests were unable to identify the cause of the production failure. Investigations by Genzyme scientists showed retrospectively that this virus had caused reduced cell productivity at its Allston and Geel, Belgium, facilities in two previous instances in 2008.

Vesivirus 2117 led to a catastrophic shortage of Cerezyme - as well as a shortage of the preparation of alphagalactosidase A for Fabry disease (Fabrazyme ${ }^{\circledR}$; Genzyme) - and with little inventory remaining, regional difficulties in supply persist to the time of writing in March 2012. The world supply and manufacture of Fabrazyme remains exiguous and provision of Cerezyme remains "hand-to-mouth" as a consequence of diminished stocks. By the end of the first quarter of the fiscal year in 2010, Genzyme reported a net loss for the first quarter of $\sim \$ 115$ million, compared with net income of $\sim \$ 196$ million in the same period in 2009 - with revenues reduced by the limited shipments of Cerezyme and Fabrazyme and constraints in product supply. This rapid decline in fortunes was compounded by a punitive charge associated with a consent decree issued by the FDA regarding the Allston manufacturing plant; this decree required an up-front disgorgement of past profits of $\$ 175$ million for the Allston manufacturing facility. Thereafter, Genzyme was forced temporarily to close its Allston plant, leading to the severe shortages of Cerezyme (and Fabrazyme for Fabry disease).

In the early phases of the crisis, competing companies were contacted by the FDA and EMA and requested to assist with the manufacture and delivery of alternatives such as velaglucerase alfa and taliglucerase alfa. ${ }^{171}$ 
The discovery of inadequate quality-control systems by regulators and the apparently hubristic ignoring of FDA demands to improve production facilities, led to further difficulties for the Genzyme company. While the loss of $30 \%$ or more of its market share for Cerezyme was a bitter blow, the injury to the reputation and perceived standards of manufacturing of this former prizewinning and highly innovative orphan drug company has been catastrophic. The supply crisis for Cerezyme sent the price of Genzyme's shares (stocks) from $\$ 84$ in 2008 to a low in early 2010 of \$45. At this point Sanofi-Aventis (from May 2011 now known as Sanofi SA), a French-based global pharmaceutical company with fortuitous and historical connections to Pasteur Mérieux, from which it originated, offered $\$ 18.5$ billion, or $\$ 69$ a share, to acquire the Genzyme Corporation. Genzyme was eventually acquired in February 2011 by Sanofi-Aventis for approximately $\$ 18$ billion. The Genzyme Corporation is now a wholly owned subsidiary of Sanofi SA.

Sanofi SA is headquartered in Paris: it has activities in cardiovascular and central nervous system diseases, diabetes, internal medicine, oncology, thrombosis, and vaccines (through its subsidiary Sanofi Pasteur it is the world's largest vaccine manufacturer). Despite this immense profile of activities, Sanofi clearly considers the developmental plans for Genzyme's hierarchy of drugs attractive for long-term investment. Genzyme's innovative program of substrate inhibiting drugs - including eliglustat tartrate for Gaucher disease - is prominent within its portfolio. ${ }^{166}$

\section{Conclusions and future prospects}

The treatment of Gaucher disease is a paradigm example of achievement in the treatment of human diseases (see Walsh ${ }^{172}$ ): based on many years of clinical and laboratory research and studies of the molecular cell biology of the lysosome, it has led the way in the specific targeting of therapeutic proteins to sites of action within diseased tissues. Potential concerns that therapeutic proteins would invoke intolerable immune reactions have, in the main, proved to be overrated: while most natural and recombinant biologic agents induce immune responses - in the case of alglucerase, imiglucerase, and other biologics - in general these are well tolerated.

The subsequent development of a recombinant human protein - imiglucerase - that can readily access cells and has the potential for manufacture in almost unlimited quantities to prevent or reverse the manifestations of disease in thousands of patients worldwide is a prodigious achievement. This success, and the attendant spectacular commercialization of a biologic agent for an ultra-orphan disease, has stimulated much productive activity in the field. In the small field of Gaucher disease this has led to the discovery of alternative means to treat the condition with innovative inhibitors of glycosphingolipid biosynthesis and the accompanying potential for related molecules to penetrate the blood-brain barrier. Not only is it now possible to utilize targeting stratagems to augment the activity of defective enzymes within cells but also the potential to deliver proteins to intracelluar targets and modify their actions offers burgeoning opportunities for therapeutic development in other diseases.

\section{Lessons that may be learned}

In the hope that future enterprise may benefit, the authors disclose an interpretation of the factors which appear to favor sustained development in the orphan disease field.

We argue that the therapeutic and commercial success of imiglucerase may be attributed to the fortuitous combination of several elements.

1. A disease that is now known to be largely reversible, at least in relation to the hematological and visceral features as well as some of its bone manifestations. Unfortunately, the neuronopathic features of Gaucher disease remain a true unmet medical need.

2. A disease, the response to treatment of which, may be readily monitored.

3. A prolonged odyssey of scientific development that culminated in specific targeting of the drug to the restricted population of cells of interest.

4. Incentives to drug development provided by orphan drug legislation.

5. Focused, dynamic commercial exploitation of a new therapeutic market.

Finally, a critical - but often unacknowledged - condition for success is the availability of not only a scientific platform but also sufficient resources and investment to take the risk. In the case of enzyme therapy for Gaucher disease, support came from government sources (the NIH), patients and their families (through the National Gaucher Foundation), and investors. Much of the enabling technology was in fact financial, and a key event, at the time, was a fusion engineered between unlikely partners. 
After the success of imiglucerase, some, even within the Genzyme organization, might have lost sight of the long scientific gestation of imiglucerase and assumed that its success could readily be replicated in other lysosomal diseases. As a result, therapeutic development programs were accelerated in diseases less amenable to correction. In Fabry disease, Pompe disease, and the mucopolysaccharidoses, the cells of interest are the principal structural and functional components of the affected organs - renal glomerular cells, cardiomyocytes, and so forth. These cells are often postmitotic or are not readily replaced from stem cell pools. The diseases progress through cell death or fibrosis, which are not normally considered reversible in the same way that pathological storage and its effects in tissue macrophages is reversible. To date, targeting these cells has depended on the display of mannose 6-phosphate residues and uptake by the cognate receptors, which are expressed in low number on the plasma membrane in many cell types.

Because orphan drug legislation provided market exclusivity to the first agent approved, the advent of competition from other biotechnology firms made a "race for the line" inevitable. In the instance of Fabry disease, Fabrazyme and Replagal ${ }^{\circledR}$ (then TKT Inc, now Shire Human Genetic Therapies) were approved in Europe by the EMA (then the European Agency for the Evaluation of Medicinal Products) on the same day in 2001 through a legislative quirk (the basis of which remains mysterious to the authors). Thus, in this winner-takes-all environment, drug development could no longer be allowed to take 20 years. It may be argued that the aim of drug development in the orphan disease area became to produce an agent adequate to meet the needs of regulatory approval in the shortest possible time, rather than to achieve a truly transformative therapy, such as imiglucerase has proved to be.

The pressures on biotechnology companies from the expectations of patient advocacy groups, shareholders, and the marketplace sometimes contributed to accelerated and abbreviated preclinical development. A possible example here relates to the development of Myozyme ${ }^{\circledR}$ (Genzyme) for Pompe disease. The authors envisage a putative scenario where Genzyme, under fierce pressure to deliver a therapy for patients, some of whom were already in clinical trials, chose to pursue the development of a protein with only one mannose 6-phosphate group per mole of protein (as compared with six for Fabrazyme, for example). Consequently, the dose required to achieve a clinical response was many times greater than other enzyme therapies $(20 \mathrm{mg} / \mathrm{kg}$ every other week, compared with $1 \mathrm{mg} / \mathrm{kg}$ every other week for Fabrazyme). Producing 20 times as much therapeutic protein was a huge manufacturing challenge and may have forced Genzyme to focus its production efforts on Myozyme at the expense of the established treatments. Thus by the time that the vesivirus infection halted production, stocks (inventory) of Cerezyme and Fabrazyme had been seriously depleted and interruptions in the supply of these agents would have been inevitable.

Although orphan drug legislation provides incentives to industry, it does not provide any mechanism to ensure that the drug will be funded. Niche orphan products are priced according to the rarity of the condition, but they are also - the authors contend - priced according to what the manufacturer believes the market will bear. With the expansion in indications for orphan products and the expectation that even common diseases such as cancers will be split into rare molecular subtypes with a view to orphan designation, the market will be able to bear less and less.

The authors urge biopharmaceutical companies, regulators, and funders of niche products to agree a more joined-up framework in which regulatory approval would require higher standards of transformative clinical efficacy in exchange for a more direct route to funding. Equally, approval and funding might be made conditional on meaningful long-term efficacy, proven in postmarketing studies. Such a funding system would reward the sort of scientific and technical innovation that led to the success of imiglucerase but would not encourage further a speculative and unsustainable biotechnology boom.

\section{Disclosure}

The authors report unrestricted research support in nonGaucher research from Genzyme and Shire HGT as well as sundry lecturing and conference fees from Actelion, Genzyme-Sanofi and Shire Human Genetic Therapies.

\section{References}

1. Barton NW, Furbish FS, Murray GJ, Garfield M, Brady RO. Therapeutic response to intravenous infusions of glucocerebrosidase in a patient with Gaucher disease. Proc Natl Acad Sci U S A. 1990;87(5):1913-1916.

2. Barton NW, Brady RO, Dambrosia JM, et al. Dose-dependent responses to macrophage-targeted glucocerebrosidase in a child with Gaucher disease. J Pediatr. 1992;120(2 Pt 1):277-280.

3. Barton NW, Brady RO, Dambrosia JM, et al. Replacement therapy for inherited enzyme deficiency - macrophage-targeted glucocerebrosidase for Gaucher's disease. N Engl J Med. 1991;324(21): 1464-1470.

4. Grabowski GA, Petsko GA, Kolodny EH. Gaucher disease. Available from: http://www.ommbid.com/OMMBID/the_online_metabolic_ and_molecular_bases_of_inherited_disease/b/abstract/part16/ch146. Accessed January 20, 2012. 
5. Futerman AH. Cellular pathology in Gaucher disease. In: Futerman AH, Zimran A, editors. Gaucher Disease. Vol 1. Boca Raton (FL): CRC Press; 2007:97-108.

6. Meikle PJ, Hopwood JJ, Clague AE, Carey WF. Prevalence of lysosomal storage disorders. JAMA. 1999;281(3):249-254.

7. Meikle PJ, Fuller M, Hopwood JJ. Epidemiology and screening policy. In: Futerman AH, Zimran A, editors. Gaucher Disease. Vol 1. Boca Raton (FL): CRC Press; 2007:321-340.

8. Grabowski GA. Gaucher disease: gene frequencies and genotype/ phenotype correlations. Genet Test. 1997;1(1):5-12.

9. Conradi N, Kyllerman M, Mansson JE, Percy AK, Svennerholm L. Late-infantile Gaucher disease in a child with myoclonus and bulbar signs: neuropathological and neurochemical findings. Acta Neuropathol. 1991;82(2):152-157.

10. Biegstraaten M, Mengel E, Maródi L, et al. Peripheral neuropathy in adult type 1 Gaucher disease: a 2-year prospective observational study. Brain. 2010;133(10):2909-2919.

11. Neudorfer O, Giladi N, Abrahamov A, et al. Occurrence of Parkinson's syndrome in type I Gaucher disease. QJM. 1996;89(9):691-694.

12. Koprivica V, Stone DL, Park JK, et al. Analysis and classification of 304 mutant alleles in patients with type 1 and type 3 Gaucher disease. Am J Hum Genet. 2000;66(6):1777-1786.

13. Hruska KS, Lamarca ME, Sidransky E. Gaucher disease: Molecular biology and genotype-phenotype correlations. In: Futerman AH, Zimran A, editors. Gaucher Disease. Boca Raton, FL: Taylor \& Francis; 2006: $13-48$.

14. Abrahamov A, Elstein D, Gross-Tsur V, et al. Gaucher's disease variant characterised by progressive calcification of heart valves and unique genotype. Lancet. 1995;346(8981):1000-1003.

15. Chabas A, Cormand B, Grinberg D, et al. Unusual expression of Gaucher's disease: cardiovascular calcifications in three sibs homozygous for the D409H mutation. J Med Genet. 1995;32(9):740-742.

16. Locatelli Hoops S, Kolter T, Sandhoff K. Saposin C and other sphingolipid activator proteins. In: Futerman A, Zimran A, editors. Gaucher Disease. Vol 1. Boca Raton (FL): CRC Press; 2007:67-84.

17. Nilsson O, Hakansson G, Dreborg S, Groth CG, Svennerholm L. Increased cerebroside concentration in plasma and erythrocytes in Gaucher disease: significant differences between type I and type III. Clin Genet. 1982;22(5):274-279.

18. Nilsson O, Mansson JE, Hakansson G, Svennerholm L. The occurrence of psychosine and other glycolipids in spleen and liver from the three major types of Gaucher's disease. Biochim Biophys Acta. 1982; 712(3):453-463.

19. Nilsson O, Svennerholm L. Accumulation of glucosylceramide and glucosylsphingosine (psychosine) in cerebrum and cerebellum in infantile and juvenile Gaucher disease. J Neurochem. 1982;39(3):709-718.

20. Lee RE. The pathology of Gaucher disease. Prog Clin Biol Res. 1982;95:177-217.

21. Lee RE. Pathologic anatomy of Gaucher disease: a pictorial essay. In: Futerman AH, Zimran A, eds. Gaucher Disease. Boca Raton: CRC Press; 2007:197-224.

22. Boven LA, van Meurs M, Boot RG, et al. Gaucher cells demonstrate a distinct macrophage phenotype and resemble alternatively activated macrophages. Am J Clin Pathol. 2004;122(3):359-369.

23. Cox TM. Gaucher disease: understanding the molecular pathogenesis of sphingolipidoses. J Inherit Metab Dis. 2001;24 Suppl 2:106-121; discussion 87-88.

24. Mistry P, Zimran A. Type 1 Gaucher disease - clinical features. In: Futerman AH, Zimran A, editors. Gaucher Disease. Vol 1. Boca Raton (FL): CRC Press; 2007:155-173.

25. Deegan PB, Pavlova E, Tindall J, et al. Osseous manifestations of Gaucher disease in the era of enzyme replacement. Medicine (Baltimore). 2011;90(1):52-60.

26. Mistry PK, Weinreb NJ, Kaplan P, Cole JA, Gwosdow AR, Hangartner T. Osteopenia in Gaucher disease develops early in life: response to imiglucerase enzyme therapy in children, adolescents and adults. Blood Cells Mol Dis. 2011;46(1):66-72.
27. Allen MJ, Myer BJ, Khokher AM, Rushton N, Cox TM. Pro-inflammatory cytokines and the pathogenesis of Gaucher's disease: increased release of interleukin-6 and interleukin-10. QJM. 1997;90(1): $19-25$.

28. Moran MT, Schofield JP, Hayman AR, Shi GP, Young E, Cox TM. Pathologic gene expression in Gaucher disease: up-regulation of cysteine proteinases including osteoclastic cathepsin K. Blood. 2000;96(5):1969-1978.

29. Grafe M, Thomas C, Schneider J, Katz B, Wiley C. Infantile Gaucher's disease: a case with neuronal storage. Ann Neurol. 1988;23(3): 300-303.

30. Conradi NG, Sourander P, Nilsson O, Svennerholm L, Erikson A. Neuropathology of the Norrbottnian type of Gaucher disease: morphological and biochemical studies. Acta Neuropathol. 1984;65(2):99-109.

31. Prabakaran T, Nielsen R, Larsen JV, et al. Receptor-mediated endocytosis of $\alpha$-galactosidase A in human podocytes in Fabry disease. PLoS One. 2011;6(9):e25065.

32. Reczek D, Schwake M, Schroder J, et al. LIMP-2 is a receptor for lysosomal mannose-6-phosphate-independent targeting of beta-glucocerebrosidase. Cell. 2007;131(4):770-783.

33. Cox TM, Schofield JP. Gaucher's disease: clinical features and natural history. Baillieres Clin Haematol. 1997;10(4):657-689.

34. Biegstraaten M, van Schaik IN, Aerts JM, et al. A monozygotic twin pair with highly discordant Gaucher phenotypes. Blood Cells Mol Dis. 2011;46(1):39-41.

35. Lachmann RH, Grant IR, Halsall D, Cox TM. Twin pairs showing discordance of phenotype in adult Gaucher's disease. QJM. 2004;97(4):199-204.

36. Tajima A, Yokoi T, Ariga M, et al. Clinical and genetic study of Japanese patients with type 3 Gaucher disease. Mol Genet Metab. 2009;97(4):272-277.

37. Jeong SY, Park SJ, Kim HJ. Clinical and genetic characteristics of Korean patients with Gaucher disease. Blood Cells Mol Dis. 2011;46(1): $11-14$.

38. Ida H, Iwasawa K, Kawame H, Rennert OM, Maekawa K, Eto Y. Characteristics of gene mutations among 32 unrelated Japanese Gaucher disease patients: absence of the common Jewish 84GG and 1226G mutations. Hum Genet. 1995;95(6):717-720.

39. Rice EO, Mifflin TE, Sakallah S, Lee RE, Sansieri CA, Barranger JA. Gaucher disease: studies of phenotype, molecular diagnosis and treatment. Clin Genet. 1996;49(3):111-118.

40. Kaplan P, Andersson HC, Kacena KA, Yee JD. The clinical and demographic characteristics of nonneuronopathic Gaucher disease in 887 children at diagnosis. Arch Pediatr Adolesc Med. 2006;160(6): 603-608.

41. Lachmann RH, Wight DG, Lomas DJ, et al. Massive hepatic fibrosis in Gaucher's disease: clinico-pathological and radiological features. QJM. 2000;93(4):237-244.

42. Kelsey H, Christopoulos C, Gray AA, Machin SJ. Acquired pseudopseudo Bernard-Soulier syndrome complicating Gaucher's disease. J Clin Pathol. 1994;47(2):162-165.

43. Simchen MJ, Oz R, Shenkman B, Zimran A, Elstein D, Kenet G. Impaired platelet function and peripartum bleeding in women with Gaucher disease. Thromb Haemost. 2011;105(3):509-514.

44. Coyne JD, Lynch T, Cotter P, Kealy WF, Duggan PF. Gaucher's disease: a case report with coincidental vitamin B12 deficiency anaemia. Ir Med J. 1985;78(9):254-255.

45. Gielchinsky Y, Elstein D, Green R, et al. High prevalence of low serum vitamin B12 in a multi-ethnic Israeli population. Br J Haematol. 2001;115(3):707-709.

46. Fleshner PR, Aufses AH Jr, Grabowski GA, Elias R. A 27-year experience with splenectomy for Gaucher's disease. Am J Surg. 1991;161(1):69-75.

47. Kyllerman M, Conradi N, Mansson JE, Percy AK, Svennerholm L. Rapidly progressive type III Gaucher disease: deterioration following partial splenectomy. Acta Paediatr Scand. 1990;79(4): 448-453. 
48. Mistry P, Sirrs S, Chan A, et al. Pulmonary hypertension in type 1 Gaucher's disease: genetic and epigenetic determinants of phenotype and response to therapy. Mol Genet Metab. 2002;77(1-2):91.

49. Blom S, Erikson A. Gaucher disease: Norrbottnian type; neurodevelopmental, neurological, and neurophysiological aspects. Eur J Pediatr. 1983;140(4):316-322.

50. Kauli R, Zaizov R, Lazar L, et al. Delayed growth and puberty in patients with Gaucher disease type 1: natural history and effect of splenectomy and/or enzyme replacement therapy. Isr Med Assoc J 2000;2(2):158-163.

51. Kaplan P, Mazur A, Manor O, et al. Acceleration of retarded growth in children with Gaucher disease after treatment with alglucerase. J Pediatr. 1996;129(1):149-153.

52. Zimran A, Morris E, Mengel E, et al. The female Gaucher patient: the impact of enzyme replacement therapy around key reproductive events (menstruation, pregnancy and menopause). Blood Cells $\mathrm{Mol}$ Dis. 2009;43(3):264-288.

53. Rosenbloom B, Balwani M, Bronstein JM, et al. The incidence of parkinsonism in patients with type 1 Gaucher disease: data from the ICGG Gaucher Registry. Blood Cells Mol Dis. 2011;46(1):95-102.

54. Westbroek W, Gustafson AM, Sidransky E. Exploring the link between glucocerebrosidase mutations and parkinsonism. Trends $\mathrm{Mol} \mathrm{Med.}$ 2011;17(9):485-493.

55. Cullen V, Sardi SP, Ng J, et al. Acid beta-glucosidase mutants linked to Gaucher disease, Parkinson disease, and Lewy body dementia alter $\alpha$-synuclein processing. Ann Neurol. 2011;69(6):940-953.

56. Sardi SP, Clarke J, Kinnecom C, et al. CNS expression of glucocerebrosidase corrects \{alpha\}-synuclein pathology and memory in a mouse model of Gaucher-related synucleinopathy. Proc Natl Acad Sci USA 2011;108(29):12101-12106.

57. Mazzulli JR, Xu YH, Sun Y, et al. Gaucher disease glucocerebrosidase and alpha-synuclein form a bidirectional pathogenic loop in synucleinopathies. Cell. 2011;146(1):37-52.

58. Gupta N, Oppenheim IM, Kauvar EF, Tayebi N, Sidransky E. Type 2 Gaucher disease: phenotypic variation and genotypic heterogeneity. Blood Cells Mol Dis. 2011;46(1):75-84.

59. Mignot C, Doummar D, Maire I, De Villemeur TB. Type 2 Gaucher disease: 15 new cases and review of the literature. Brain Dev. 2006;28(1):39-48

60. Cindik N, Ozcay F, Suren D, et al. Gaucher disease with communicating hydrocephalus and cardiac involvement. Clin Cardiol. 2010;33(1): E26-E30.

61. Uyama E, Takahashi K, Owada M, et al. Hydrocephalus, corneal opacities, deafness, valvular heart disease, deformed toes and leptomeningeal fibrous thickening in adult siblings: a new syndrome associated with beta-glucocerebrosidase deficiency and mosaic population of storage cells. Acta Neurol Scand. 1992;86(4):407-420.

62. Uyama E, Uchino M, Ida H, Eto Y, Owada M. D409H/D409H genotype in Gaucher-like disease. J Med Genet. 1997;34(2):175.

63. George R, McMahon J, Lytle B, Clark B, Lichtin A. Severe valvular and aortic arch calcification in a patient with Gaucher's disease homozygous for the D409H mutation. Clin Genet. 2001;59(5):360-363.

64. Aksu T, Baysal E, Biyikoglu F, Tufekcioglu O. Gaucher's disease with valvular, myocardial and aortic involvement in a patient with oculomotor apraxia. Anadolu Kardiyol Derg. 2011;11(1):E4-E5.

65. Erduran E, Mocan H, Gedik Y, Kamaci R, Okten A, Deger O. Hydrocephalus, corneal opacities, deafness, left ventricle hypertrophy, clinodactyly in an adolescent patient: a new syndrome associated with glucocerebrosidase deficiency. Genet Couns. 1995;6(3):211-215.

66. Zimran A, Kay A, Gelbart T, et al. Gaucher disease. Clinical, laboratory, radiologic, and genetic features of 53 patients. Medicine (Baltimore). 1992;71(6):337-353.

67. Weinreb NJ, Deegan P, Kacena KA, et al. Life expectancy in Gaucher disease type 1. Am J Hematol. 2008;83(12):896-900.

68. Rosenbloom BE, Weinreb NJ, Zimran A, Kacena KA, Charrow J, Ward E. Gaucher disease and cancer incidence: a study from the Gaucher Registry. Blood. 2005;105(12):4569-4572.
69. De Fost M, Vom Dahl S, Weverling GJ, et al. Increased incidence of cancer in adult Gaucher disease in Western Europe. Blood Cells $\mathrm{Mol}$ Dis. 2006;36(1):53-58.

70. Deegan PB, Moran MT, McFarlane I, et al. Clinical evaluation of chemokine and enzymatic biomarkers of Gaucher disease. Blood Cells Mol Dis. 2005;35(2):259-267.

71. Bracoud L, Ahmad H, Brill-Almon E, Chertkoff R. Improving the accuracy of MRI spleen and liver volume measurements: a phase III Gaucher disease clinical trial setting as a model. Blood Cells Mol Dis. 2011;46(1):47-52.

72. Maas M, Poll LW, Terk MR. Imaging and quantifying skeletal involvement in Gaucher disease. Br J Radiol. 2002;75 Suppl 1:A13-A24.

73. Bembi B, Ciana G, Mengel E, Terk MR, Martini C, Wenstrup RJ. Bone complications in children with Gaucher disease. Br J Radiol. 2002; 75 Suppl 1:A37-A44.

74. Ciana G, Addobbati R, Tamaro G, et al. Gaucher disease and bone: laboratory and skeletal mineral density variations during a long period of enzyme replacement therapy. J Inherit Metab Dis. 2005;28(5):723-732.

75. Andersson H, Kaplan P, Kacena K, Yee J. Eight-year clinical outcomes of long-term enzyme replacement therapy for 884 children with Gaucher disease type 1. Pediatrics. 2008;122(6):1182-1190.

76. Sims KB, Pastores GM, Weinreb NJ, et al. Improvement of bone disease by imiglucerase (Cerezyme) therapy in patients with skeletal manifestations of type 1 Gaucher disease: results of a 48-month longitudinal cohort study. Clin Genet. 2008;73(5):430-440.

77. Damiano AM, Pastores GM, Ware JE Jr. The health-related quality of life of adults with Gaucher's disease receiving enzyme replacement therapy: results from a retrospective study. Qual Life Res. 1998;7(5): 373-386.

78. Hayes RP, Grinzaid KA, Duffey EB, Elsas LJ 2nd. The impact of Gaucher disease and its treatment on quality of life. Qual Life Res. 1998;7(6):521-534.

79. Weinreb N, Barranger J, Packman S, et al. Imiglucerase (Cerezyme) improves quality of life in patients with skeletal manifestations of Gaucher disease. Clin Genet. 2007;71(6):576-588.

80. Wraith JE, Clarke LA, Beck M, et al. Enzyme replacement therapy for mucopolysaccharidosis I: a randomized, double-blinded, placebo-controlled, multinational study of recombinant human alpha-L-iduronidase (laronidase). J Pediatr. 2004;144(5):581-588.

81. Muenzer J, Wraith JE, Beck M, et al. A phase II/III clinical study of enzyme replacement therapy with idursulfase in mucopolysaccharidosis II (Hunter syndrome). Genet Med. 2006;8(8):465-473.

82. Harmatz P, Giugliani R, Schwartz I, et al. Enzyme replacement therapy for mucopolysaccharidosis VI: a phase 3, randomized, double-blind, placebo-controlled, multinational study of recombinant human $\mathrm{N}$-acetylgalactosamine 4-sulfatase (recombinant human arylsulfatase B or rhASB) and follow-on, open-label extension study. J Pediatr. 2006;148(4):533-539.

83. MacDermot KD, Holmes A, Miners AH. Anderson-Fabry disease: clinical manifestations and impact of disease in a cohort of 98 hemizygous males. J Med Genet. 2001;38(11):750-760.

84. Eng CM, Guffon N, Wilcox WR, et al. Safety and efficacy of recombinant human alpha-galactosidase A: replacement therapy in Fabry's disease. N Engl J Med. 2001;345(1):9-16.

85. Germain DP, Waldek S, Banikazemi M, et al. Sustained, long-term renal stabilization after 54 months of agalsidase beta therapy in patients with Fabry disease. J Am Soc Nephrol. 2007;18(5):1547-1557.

86. Brady RO, Kanfer JN, Bradley RM, Shapiro D. Demonstration of a deficiency of glucocerebroside-cleaving enzyme in Gaucher's disease. J Clin Invest. 1966;45(7):1112-1115.

87. Weinreb NJ, Brady RO, Tappel AL. The lysosomal localization of sphingolipid hydrolases. Biochim Biophys Acta. 1968;159(1):141-146.

88. De Duve C. The lysosome. Sci Am. 1963;208:64-72.

89. Appelmans F, Wattiaux R, de Duve C. Tissue fractionation studies: 5 . The association of acid phosphatase with a special class of cytoplasmic granules in rat liver. Biochem J. 1955;59(3):438-445. 
90. Fratantoni JC, Hall CW, Neufeld EF. Hurler and Hunter syndromes: mutual correction of the defect in cultured fibroblasts. Science. 1968;162(853):570-572.

91. Hickman S, Shapiro LJ, Neufeld EF. A recognition marker required for uptake of a lysosomal enzyme by cultured fibroblasts. Biochem Biophys Res Commun. 1974;57(1):55-61.

92. Kaplan A, Achord DT, Sly WS. Phosphohexosyl components of a lysosomal enzyme are recognized by pinocytosis receptors on human fibroblasts. Proc Natl Acad Sci U S A. 1977;74(5): 2026-2030.

93. Sando GN, Neufeld EF. Recognition and receptor-mediated uptake of a lysosomal enzyme, alpha-1-iduronidase, by cultured human fibroblasts. Cell. 1977;12(3):619-627.

94. Kornfeld S. A fascination with sugars. Mol Biol Cell. 2010;21(22): 3773-3775.

95. Hasilik A, Waheed A, Cantz M, von Figura K. Oligosaccharides in lysosomal enzymes. Distribution of high-mannose and complex oligosaccharides in cathepsin D and beta-hexosaminidase. Eur J Biochem. 1982;122(1):119-123.

96. Aerts JM, Schram AW, Strijland A, et al. Glucocerebrosidase, a lysosomal enzyme that does not undergo oligosaccharide phosphorylation. Biochim Biophys Acta. 1988;964(3):303-308.

97. Brady RO, Pentchev PG, Gal AE, Hibbert SR, Dekaban AS. Replacement therapy for inherited enzyme deficiency. Use of purified glucocerebrosidase in Gaucher's disease. NEngl J Med. 1974;291(19): 989-993.

98. Furbish FS, Blair HE, Shiloach J, Pentchev PG, Brady RO. Enzyme replacement therapy in Gaucher's disease: large-scale purification of glucocerebrosidase suitable for human administration. Proc Natl Acad Sci U S A. 1977;74(8):3560-3563.

99. Dale GL, Beutler E. Enzyme replacement therapy in Gaucher's disease: a rapid, high-yield method for purification of glucocerebrosidase. Proc Natl Acad Sci U S A. 1976;73(12):4672-4674.

100. Dale GL, Villacorte DG, Beutler E. Solubilization of glucocerebrosidase from human placenta and demonstration of a phospholipid requirement for its catalytic activity. Biochem Biophys Res Commun. 1976;71(4):1048-1053.

101. Brady RO, Pentchev PG, Gal AE, et al. Enzyme replacement therapy for the sphingolipidoses. Adv Exp Med Biol. 1976;68: 523-532.

102. Furbish FS, Steer CJ, Barranger JA, Jones EA, Brady RO. The uptake of native and desialylated glucocerebrosidase by rat hepatocytes and Kupffer cells. Biochem Biophys Res Commun. 1978;81(3): 1047-1053.

103. Brady RO. Enzyme replacement in the sphingolipidoses. In: Barranger J, Brady RO, editors. Molecular Basis of Lysosomal Storage Disorders. Vol 1. Orlando (FL): Academic Press; 1984:461-478.

104. Morrone S, Pentchev PG, Baynes J, Thorpe S. Studies in vivo of the tissue uptake, cellular distribution and catabolic turnover of exogenous glucocerebrosidase in rat. Biochem J. 1981;194(3): 733-742.

105. Beutler E, Dale GL, Guinto DE, Kuhl W. Enzyme replacement therapy in Gaucher's disease: preliminary clinical trial of a new enzyme preparation. Proc Natl Acad Sci U S A. 1977;74(10):4620-4623.

106. Dale GL, Kuhl W, Beutler E. Incorporation of glucocerebrosidase into Gaucher's disease monocytes in vitro. Proc Natl Acad Sci USA. 1979;76(1):473-475.

107. Hudgin RL, Pricer WE Jr, Ashwell G, Stockert RJ, Morell AG. The isolation and properties of a rabbit liver binding protein specific for asialoglycoproteins. J Biol Chem. 1974;249(17):5536-5543.

108. Neufeld EF. From serendipity to therapy. Annu Rev Biochem. 2011; 80:1-15.

109. Stahl PD, Rodman JS, Miller MJ, Schlesinger PH. Evidence for receptor-mediated binding of glycoproteins, glycoconjugates, and lysosomal glycosidases by alveolar macrophages. Proc Natl Acad Sci US A. 1978;75(3):1399-1403.
110. Robbins JC, Lam MH, Tripp CS, Bugianesi RL, Ponpipom MM, Shen TY. Synthetic glycopeptide substrates for receptor-mediated endocytosis by macrophages. Proc Natl Acad Sci U SA. 1981;78(12): 7294-7298.

111. Achord DT, Brot FE, Bell CE, Sly WS. Human beta-glucuronidase: in vivo clearance and in vitro uptake by a glycoprotein recognition system on reticuloendothelial cells. Cell. 1978;15(1):269-278.

112. Takasaki S, Murray GJ, Furbish FS, Brady RO, Barranger JA, Kobata A. Structure of the N-asparagine-linked oligosaccharide units of human placental beta-glucocerebrosidase. J Biol Chem. 1984;259(16):10112-10117.

113. Furbish FS, Oliver KL, Zirzow GC, Brady RO, Barranger JA. Interaction of human placental glucocerebrosidase with hepatic lectins. In: Barranger JA, Brady RO, editors. The Molecular Basis of Lysosomal Storage Disorders. Orlando (FL): Academic Press; 1984:219-232.

114. Pricer WE Jr, Hudgin RL, Ashwell G, Stockert RJ, Morell AG. A membrane receptor protein for asialoglycoproteins. Methods Enzymol. 1974;34:688-691.

115. Furbish FS, Steer CJ, Krett NL, Barranger JA. Uptake and distribution of placental glucocerebrosidase in rat hepatic cells and effects of sequential deglycosylation. Biochim Biophys Acta. 1981;673(4):425-434.

116. Doebber TW, Wu MS, Bugianesi RL, et al. Enhanced macrophage uptake of synthetically glycosylated human placental betaglucocerebrosidase. J Biol Chem. 1982;257(5):2193-2199.

117. Murray GJ. Lectin-specific targeting of lysosomal enzymes to reticuloendothelial cells. Methods Enzymol. 1987;149:25-42.

118. Natowicz MR, Chi MM, Lowry OH, Sly WS. Enzymatic identification of mannose 6-phosphate on the recognition marker for receptormediated pinocytosis of beta-glucuronidase by human fibroblasts. Proc Natl Acad Sci U S A. 1979;76(9):4322-4326.

119. Parker RI, Barton NW, Read EJ, Brady RO. Hematologic improvement in a patient with Gaucher disease on long-term enzyme replacement therapy: evidence for decreased splenic sequestration and improved red blood cell survival. Am J Hematol. 1991;38(2):130-137.

120. Murray GJ, Howard KD, Richards SM, Barton NW, Brady RO. Gaucher's disease: lack of antibody response in 12 patients following repeated intravenous infusions of mannose terminal glucocerebrosidase. J Immunol Methods. 1991;137(1):113-120.

121. Richards SM, Olson TA, McPherson JM. Antibody response in patients with Gaucher disease after repeated infusion with macrophage-targeted glucocerebrosidase. Blood. 1993;82(5):1402-1409.

122. Beutler E, Kay A, Saven A, et al. Enzyme replacement therapy for Gaucher disease. Blood. 1991;78(5):1183-1189.

123. Fallet S, Grace ME, Sibille A, et al. Enzyme augmentation in moderate to life-threatening Gaucher disease. Pediatr Res. 1992;31(5): 496-502.

124. Mistry PK, Davies S, Corfield A, Dixon AK, Cox TM. Successful treatment of bone marrow failure in Gaucher's disease with low-dose modified glucocerebrosidase. Q J Med. 1992;83(303): 541-546.

125. Grabowski GA, Barton NW, Pastores G, et al. Enzyme therapy in type 1 Gaucher disease: comparative efficacy of mannose-terminated glucocerebrosidase from natural and recombinant sources. Ann Intern Med. 1995;122(1):33-39.

126. Mistry PK, Wraight EP, Cox TM. Therapeutic delivery of proteins to macrophages: implications for treatment of Gaucher's disease. Lancet. 1996;348(9041):1555-1559.

127. Friedman B, Vaddi K, Preston C, Mahon E, Cataldo JR, McPherson JM. A comparison of the pharmacological properties of carbohydrate remodeled recombinant and placental-derived beta-glucocerebrosidase: implications for clinical efficacy in treatment of Gaucher disease. Blood. 1999;93(9):2807-2816.

128. Hollak CE, Aerts JM, Goudsmit R, et al. Individualised low-dose alglucerase therapy for type 1 Gaucher's disease. Lancet. 1995;345(8963): $1474-1478$. 
129. Figueroa ML, Rosenbloom BE, Kay AC, et al. A less costly regimen of alglucerase to treat Gaucher's disease. N Engl J Med. 1992;327(23): $1632-1636$.

130. Mistry PK, Weinreb NJ, Brady RO, Grabowski GA. Gaucher disease: resetting the clinical and scientific agenda. Am J Hematol. 2009;84(4) 205-207.

131. Zimran A, Ilan Y, Elstein D. Enzyme replacement therapy for mild patients with Gaucher disease. Am J Hematol. 2009;84(4):202-204.

132. Hollak CE, van Weely S, van Oers MH, Aerts JM. Marked elevation of plasma chitotriosidase activity. A novel hallmark of Gaucher disease. J Clin Invest. 1994;93(3):1288-1292.

133. Pastores GM, Weinreb NJ, Aerts H, et al. Therapeutic goals in the treatment of Gaucher disease. Semin Hematol. 2004;41(4 Suppl 5):4-14.

134. Weinreb N, Taylor J, Cox T, Yee J, vom Dahl S. A benchmark analysis of the achievement of therapeutic goals for type 1 Gaucher disease patients treated with imiglucerase. Am J Hematol. 2008;83(12):890-895.

135. Grabowski GA, Kacena K, Cole JA, et al. Dose-response relationships for enzyme replacement therapy with imiglucerase/alglucerase in patients with Gaucher disease type 1. Genet Med. 2009;11(2) 92-100.

136. Goldman DP, Clarke AE, Garber AM. Creating the costliest orphan: the Orphan Drug Act in the development of Ceredase. Int J Technol Assess Health Care. 1992;8(4):583-597.

137. Connock M, Burls A, Frew E, et al. The clinical effectiveness and cost-effectiveness of enzyme replacement therapy for Gaucher's disease: a systematic review. Health Technol Assess. 2006;10(24):iii-iv, ix -136 .

138. Meeker D, Termeer HA. Meeting the needs of patients with Gaucher disease: pioneering a sustainable model for ultra-orphan diseases. In: Futerman AH, Zimran A, editors. Gaucher Disease. Vol 1. Boca Raton (FL): CRC Press; 2007:465-472.

139. Charrow J, Dulisse B, Grabowski GA, Weinreb NJ. The effect of enzyme replacement therapy on bone crisis and bone pain in patients with type 1 Gaucher disease. Clin Genet. 2007;71(3):205-211.

140. Starzyk K, Richards S, Yee J, Smith SE, Kingma W. The long-term international safety experience of imiglucerase therapy for Gaucher disease. Mol Genet Metab. 2007;90(2):157-163.

141. Cox TM, Aerts JM, Belmatoug N, et al. Management of nonneuronopathic Gaucher disease with special reference to pregnancy, splenectomy, bisphosphonate therapy, use of biomarkers and bone disease monitoring. J Inherit Metab Dis. 2008;31(3):319-336.

142. Wenstrup RJ, Bailey L, Grabowski GA, et al. Gaucher disease: alendronate disodium improves bone mineral density in adults receiving enzyme therapy. Blood. 2004;104(5):1253-1257.

143. Lebel E, Dweck A, Foldes AJ, et al. Bone density changes with enzyme therapy for Gaucher disease. J Bone Miner Metab. 2004;22(6): 597-601.

144. Rudzki Z, Okon K, Machaczka M, Rucinska M, Papla B, Skotnicki AB Enzyme replacement therapy reduces Gaucher cell burden but may accelerate osteopenia in patients with type I disease: a histological study. Eur J Haematol. 2003;70(5):273-281.

145. Marini JC. Do bisphosphonates make children's bones better or brittle? N Engl J Med. 2003;349(5):423-426.

146. Bembi B, Agosti E, Boehm P, Nassimbeni G, Zanatta M, Vidoni L. Aminohydroxypropylidene-biphosphonate in the treatment of bone lesions in a case of Gaucher's disease type 3. Acta Paediatr. 1994;83(1): $122-124$.

147. Ostlere L, Warner T, Meunier PJ, et al. Treatment of type 1 Gaucher's disease affecting bone with aminohydroxypropylidene bisphosphonate (pamidronate). Q J Med. 1991;79(290):503-515.

148. Rosenbaum H, Sidransky E. Cholelithiasis in patients with Gaucher disease. Blood Cells Mol Dis. 2002;28(1):21-27.

149. Taddei TH, Dziura J, Chen S, et al. High incidence of cholesterol gallstone disease in type 1 Gaucher disease: characterizing the biliary phenotype of type 1 Gaucher disease. J Inherit Metab Dis. 2010;33(3): 291-300.
150. Lo SM, Liu J, Chen F, et al. Pulmonary vascular disease in Gaucher disease: clinical spectrum, determinants of phenotype and long-term outcomes of therapy. J Inherit Metab Dis. 2011;34(3):643-650.

151. Cox T, Lachmann R, Hollak C, et al. Novel oral treatment of Gaucher's disease with N-butyldeoxynojirimycin (OGT 918) to decrease substrate biosynthesis. Lancet. 2000;355(9214):1481-1485.

152. Elstein D, Hollak C, Aerts JM, et al. Sustained therapeutic effects of oral miglustat (Zavesca, N-butyldeoxynojirimycin, OGT 918) in type I Gaucher disease. J Inherit Metab Dis. 2004;27(6):757-766.

153. Cox TM, Aerts JM, Andria G, et al. The role of the iminosugar N-butyldeoxynojirimycin (miglustat) in the management of type I (non-neuronopathic) Gaucher disease: a position statement. J Inherit Metab Dis. 2003;26(6):513-526.

154. Brumshtein B, Salinas P, Peterson B, et al. Characterization of geneactivated human acid-beta-glucosidase: crystal structure, glycan composition, and internalization into macrophages. Glycobiology. 2010;20(1):24-32.

155. Van Patten SM, Hughes H, Huff MR, et al. Effect of mannose chain length on targeting of glucocerebrosidase for enzyme replacement therapy of Gaucher disease. Glycobiology. 2007;17(5):467-478.

156. Zimran A, Altarescu G, Philips M, et al. Phase $1 / 2$ and extension study of velaglucerase alfa replacement therapy in adults with type 1 Gaucher disease: 48-month experience. Blood. 2010;115(23): 4651-4656.

157. Elstein D, Cohn GM, Wang N, Djordjevic M, Brutaru C, Zimran A. Early achievement and maintenance of the therapeutic goals using velaglucerase alfa in type 1 Gaucher disease. Blood Cells Mol Dis. 2011;46(1):119-123.

158. Elstein D, Foldes AJ, Zahrieh D, et al. Significant and continuous improvement in bone mineral density among type 1 Gaucher disease patients treated with velaglucerase alfa: 69-month experience, including dose reduction. Blood Cells Mol Dis. 2011;47(1):56-61.

159. Shaaltiel Y, Bartfeld D, Hashmueli S, et al. Production of glucocerebrosidase with terminal mannose glycans for enzyme replacement therapy of Gaucher's disease using a plant cell system. Plant Biotechnol J. 2007;5(5):579-590.

160. Aviezer D, Brill-Almon E, Shaaltiel Y, et al. A plant-derived recombinant human glucocerebrosidase enzyme: a preclinical and phase I investigation. PLoS One. 2009;4(3):e4792.

161. Zimran A, Brill-Almon E, Chertkoff R, et al. Pivotal trial with plant cell-expressed recombinant glucocerebrosidase, taliglucerase alfa, a novel enzyme replacement therapy for Gaucher disease. Blood. 2011;118(22):5767-5773.

162. Inokuchi J, Radin NS. Preparation of the active isomer of 1-phenyl2-decanoylamino-3-morpholino-1-propanol, inhibitor of murine glucocerebroside synthetase. J Lipid Res. 1987;28(5):565-571.

163. Abe A, Radin NS, Shayman JA, et al. Structural and stereochemical studies of potent inhibitors of glucosylceramide synthase and tumor cell growth. J Lipid Res. 1995;36(3):611-621.

164. McEachern KA, Fung J, Komarnitsky S, et al. A specific and potent inhibitor of glucosylceramide synthase for substrate inhibition therapy of Gaucher disease. Mol Genet Metab. 2007;91(3):259-267.

165. Lee L, Abe A, Shayman JA. Improved inhibitors of glucosylceramide synthase. J Biol Chem. 1999;274(21):14662-14669.

166. Cox TM. Eliglustat tartrate, an orally active glucocerebroside synthase inhibitor for the potential treatment of Gaucher disease and other lysosomal storage diseases. Curr Opin Investig Drugs. 2010;11(10):1169-1181.

167. Peterschmitt MJ, Burke A, Blankstein L, et al. Safety, tolerability, and pharmacokinetics of eliglustat tartrate (Genz-112638) after single doses, multiple doses, and food in healthy volunteers. J Clin Pharmacol. 2011;51(5):695-705.

168. Lukina E, Watman N, Arreguin EA, et al. Improvement in hematological, visceral, and skeletal manifestations of Gaucher disease type 1 with oral eliglustat tartrate (Genz-112638) treatment: 2-year results of a phase 2 study. Blood. 2010;116(20):4095-4098. 
169. Weinreb NJ, Charrow J, Andersson HC, et al. Effectiveness of enzyme replacement therapy in 1028 patients with type 1 Gaucher disease after 2 to 5 years of treatment: a report from the Gaucher Registry. Am J Med. 2002;113(2):112-119.

170. Roos JC, Hyry HI, Cox TM. Orphan drug pricing may warrant a competition law investigation. BMJ. 2010;341:c6471.
171. Hollak CE, vom Dahl S, Aerts JM, et al. Force majeure: therapeutic measures in response to restricted supply of imiglucerase (Cerezyme) for patients with Gaucher disease. Blood Cells Mol Dis. 2010;44(1): 41-47.

172. Walsh G. Biopharmaceutical benchmarks 2010. Nat Biotechnol. 2010;28(9):917-924.

\section{Publish your work in this journal}

Drug Design, Development and Therapy is an international, peerreviewed open-access journal that spans the spectrum of drug design and development through to clinical applications. Clinical outcomes, patient safety, and programs for the development and effective, safe, and sustained use of medicines are a feature of the journal, which has also been accepted for indexing on PubMed Central. The manuscript management system is completely online and includes a very quick and fair peer-review system, which is all easy to use. Visit http://www.dovepress.com/testimonials.php to read real quotes from published authors.

Submit your manuscript here: http://www.dovepress.com/drug-design-development-and-therapy-journal 